\title{
Cerro Colorado: un asentamiento de época púnica en la costa occidental malagueña
}

\author{
Cerro Colorado: a village of punic epoch on the western coast \\ of malaga
}

Salvador Bravo JimÉnez* y Antonio Soto IborRa

\begin{abstract}
RESUMEN ABSTRACT
Con motivo de la construcción de unas villas de lujo en la costa marbellí, tuvimos la oportunidad de excavar en extensión el yacimiento que nos ocupa, excavación de la que presentamos sus resultados debido a la magnitud de los hallazgos aparecidos y que pueden arrojar luz sobre uno de los periodos peor conocidos en la zona adyacente del estrecho de Gibraltar como es el de la Segunda Guerra Púnica.

PALABRAS CLAVE: Cartasgineses, Muralla, Monedas.

In the occasion of the construction of villas of luxury in the marbelli coast, we had the opportunity to excavate in extension the deposit that occupies to us, excavation of which we presented its results due to the magnitude of the appeared findings and that they can throw light on one of the periods worse known in the adjacent zone of the Straits of Gibraltar as is the Second Punic War.

KEYWORDS:

Cartaginians, Wall, Coins
\end{abstract}

\section{INTRODUCCIÓN}

Durante los trabajos de prospección arqueológica acometidos previamente a la ejecución de la Autopista Costa del Sol (tramo Marbella-Estepona) (Mayorga, J. 2001: 360), se constató la existencia de un oppidum prerromano con la presencia en superficie de estructuras antiguas y abundante material cerámico.

El estado que presentaba este material se podía calificar de aceptable con escasos índices de rodamiento y un porcentaje de concreción de tipo medio con una cronología comprendida entre los siglos IV-I a.C.

* UNED. C. A. Campo de Gibraltar. Centro Cívico «La Reconquista», s/n. 11202 Algeciras (Cádiz). E-mail: salva@algeciras.uned.es 
Respecto al estado de conservación, el grado de erosión alcanzaba niveles medio-altos detectándose a su vez incidencias de carácter antrópico, materializadas en trabajos de abancalamiento de algunas de sus laderas y la construcción de un vial de acceso a la cima del promontorio.

Pese a ello el estado general de conservación fue estimado como bueno, estableciéndose como propuesta de medidas correctoras la realización de sondeos previos con carácter preventivo en función al interés patrimonial y científico del yacimiento. Sin embargo, unas obras incontroladas en 1999 produjeron un amesetamiento artificial con la pérdida de más de 5 metros de potencia estratigráfica.

La propuesta de ejecución de un proyecto urbanístico en el área, hacía imprescindible la realización de una actividad arqueológica de carácter preventivo, en cumplimiento con la legislación vigente andaluza en materia de protección y conservación del Patrimonio Arqueológico que tuvo lugar en julio de 2004, contemplándose la realización de sondeos de delimitación del área de protección arqueológica ( 10 sondeos denominados $\mathrm{A}$ a J) con unas dimensiones de $5 \times 2.5$ metros.

Los resultados aportados por dicha intervención arqueológica fueron detallados en el preceptivo Informe Preliminar ${ }^{1}$, concluyéndose que el poblado se ubicaba en las cotas altas (145-140 m.s.n.m) y medias (135-125 m.s.n.m) de Cerro Colorado, un promontorio amesetado situado en la margen derecha del río Guadaiza, en un contexto muy próximo al mar en época protohistórica conformando un amplio delta, tal y como apuntan los datos aportados por el estudio paleotopográfico de cursos fluviales cercanos (MAYORGA, J. 2001: 363).

Esta intervención supuso una primera aproximación a las características y naturaleza del yacimiento, resultando determinante de cara a obtener la delimitación espacial del mismo, considerando que habría que determinarse con mayor precisión todos aquellos aspectos relacionados con la caracterización cronológica, espacial y funcional del yacimiento, objetivos éstos no contemplados en el desarrollo de la primera campaña de intervenciones arqueológicas.

En virtud a los resultados aportados por la intervención del 2004, la Delegación Provincial de Cultura de la Consejería de Cultura de la Junta de Andalucía resolvió la autorización para llevar a cabo una nueva actividad arqueológica que se llevó a cabo entre los meses de agosto a noviembre de 2005 cuyos resultados fundamentan este trabajo.

\section{UBICACIÓN DEL ASENTAMIENTO (Lám. 1)}

Se sitúa en un promontorio elevado con una cota de 146 m.s.n.d.m. en la margen derecha del río Guadaiza (Fig. 1) a unos 4, $5 \mathrm{Km}$ de la línea costera actual aunque pensamos que a finales del primer milenio a.n.e. la línea de costa debería estar más cercana al yacimiento, en torno a poco menos de 900 metros aunque

1 Informe depositado en la Delegación Provincial de Cultura en Málaga con fecha 5 de octubre de 2004. 


\section{Vista general del yacimiento}
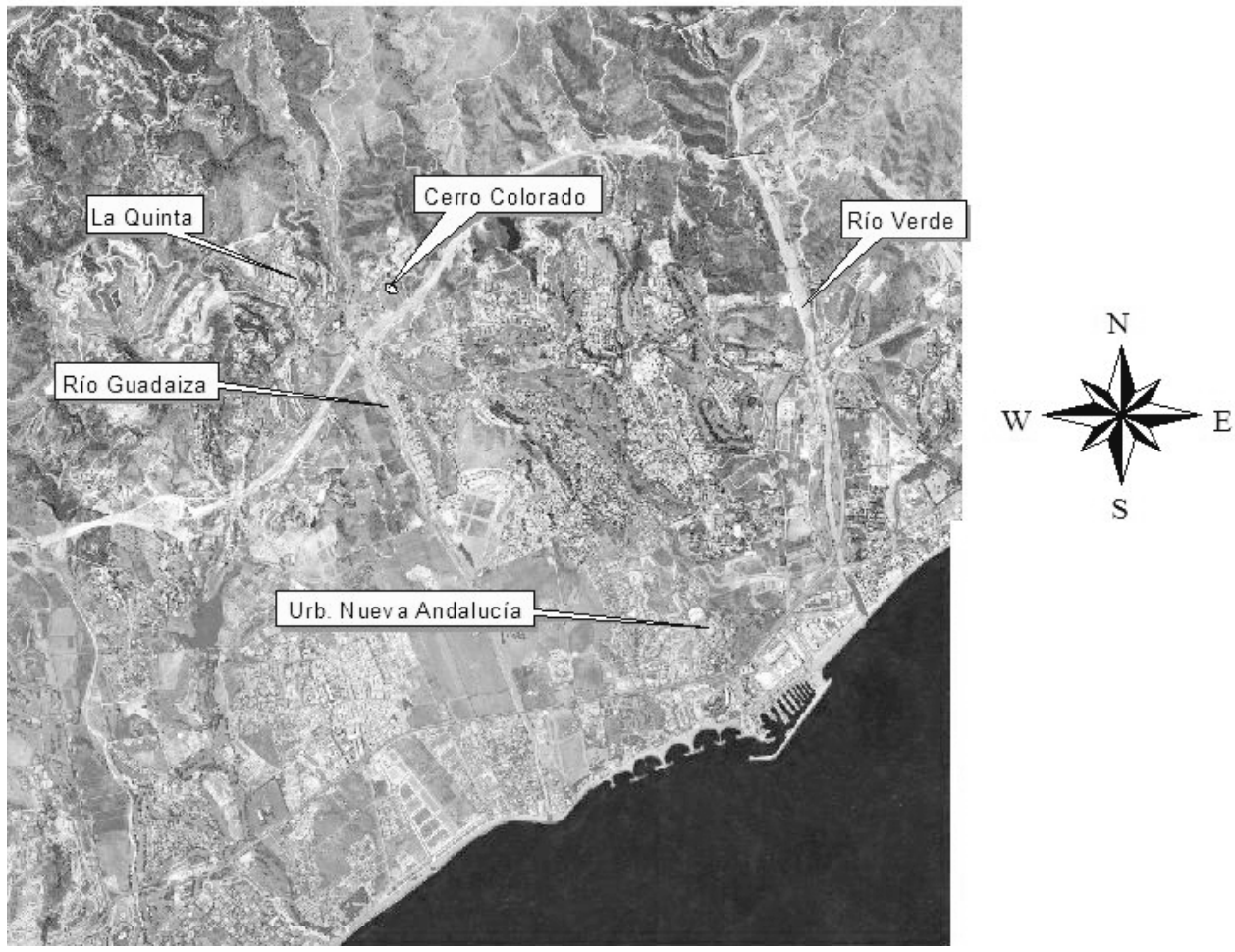

Fig. 1. Ubicación de Cerro Colorado.

seguramente el río sería navegable para embarcaciones de poco calado lo que entraña la posibilidad de que el propio asentamiento tuviera algún tipo de instalación portuaria en la parte más cercana al río. La masiva presencia de envases anfóricos destinados a las producciones marinas así como el hallazgo de pesas de red nos hace barajar la posibilidad de que nuestro cerro se encontrara en un ambiente bastante más cercano al mar de lo que a simple vista pueda parecer en la actualidad.

\section{METODOLOGÍA}

Los trabajos arqueológicos se centraron en dos zonas con vistas a la delimitación del yacimiento: La primera de ellas es la meseta superior, formada por una dolina amesetada artificialmente en 1999 con maquinaria pesada lo que originó un rebaje mecánico sin control arqueológico de unos 5 metros de potencia.

Se realizaron 7 sondeos en la meseta superior del yacimiento a fin de comprobar el estado de conservación de estructuras antiguas conservadas y tres zanjas para delimitar el asentamiento en las laderas Oeste, Norte y Sur. 
De este modo, los objetivos planteados para esta fase atendieron a la consecución de una doble finalidad:

1. Documentación sistemática y extensiva de las estructuras arqueológicas que definen la parte alta del poblado, localizado en el borde superior del coronamiento del cerro.

2. Evaluación del potencial arqueológico de las laderas del yacimiento. Para ello se plantearon un total de tres trincheras de diagnosis cuya longitud correspondió aproximadamente con el desarrollo de cada una de las laderas, desde las cotas más altas del promontorio hasta las cotas inferiores del yacimiento.

Atendiendo a estos argumentos la actividad llevada a cabo contempló dos actuaciones:

La primera propuesta se centró en la excavación en extensión de la zona superior del poblado. Los trabajos se centraron pues en las cotas superiores del promontorio, ocupando las áreas no afectadas por el rebaje mecánico incontrolado efectuado sobre el yacimiento. La elección de esta zona se fundamentó en su potencialidad arqueológica y la conservabilidad que - a priori - presentaron las estructuras documentadas durante la fase anterior, circunstancias que justificaban la atención de la investigación en este sector del poblado.

La segunda intervención que propusimos se localizó en las laderas del asentamiento. Para ello se planteó un sistema de diagnosis basado en la realización de tres trincheras o transets que se desarrollaron desde las cotas superiores del poblado.

Su distribución se determinó en función de la concentración en superficie de posibles estructuras arqueológicas detectadas durante la campaña anterior. Esta circunstancia explica una mayor densidad de superficie de investigación planteada en la ladera sur del asentamiento, área que por sus características físicas presentaba un mayor índice de ocupación.

La localización, denominación y dimensiones aproximadas de estas trincheras se muestran en la tabla que sigue:

Ladera Norte: Zanja C: $20 \times 2 \mathrm{~m}$.

Ladera Sur: Zanja A: $27 \times 2 \mathrm{~m}$.

Ladera Oeste: Zanja B: $17 \times 2 \mathrm{~m}$.

Con el objeto de proporcionar versatilidad a los trabajos arqueológicos procedimos a la utilización de un sistema basado en la sectorización de las zonas lo cual posibilitó reducir o ampliar el área de excavación - en él caso de las necesidades planteadas durante la excavación - y siempre en función de los datos suministrados por el propio desarrollo de la actividad arqueológica.

Los trabajos fueron dirigidos por D. Antonio Soto Iborra con el apoyo de un equipo de investigación formado por D. Salvador Bravo Jiménez y por D. José Suá- 
rez Padilla. Se contó con una plantilla de estudiantes de la Universidad de Málaga y de la Universidad Complutense de Madrid².

Los sondeos fueron nominados mediante letras mayúsculas del alfabeto continuando con la nomenclatura de la campaña de 2004 comenzando por el llamado Sondeo K en la parte Oeste de la meseta superior y finalizando con el Sondeo P en la parte Este de dicha meseta. Se siguió un orden similar al de las agujas del reloj en cuanto a su denominación recorriendo la citada meseta. Por tanto, los Sondeos $L$ y $\mathrm{M}$ se encuentran en la zona Oeste del cerro, el Sondeo $\mathrm{N}$ al Norte y los Sondeos $\tilde{N}$, O y P en la zona Este de la meseta superior.

Las zanjas fueron nominadas según el alfabeto comenzando por la A. Quedaron ubicadas en las laderas Sur, Oeste y Norte toda vez que la ladera Este del yacimiento fue totalmente arrasada por trabajos de construcción actuales a lo que hay que unir la aspereza del terreno que hacía prácticamente imposible acometer cualquier trabajo arqueológico debido a la acusada pendiente.

La Zanja A se ubicó en la ladera Sur del cerro, subdividida en tres transets llamados de Norte a Sur, A/1, A/2 y A/3. La Zanja B quedó planteada en la ladera Oeste del yacimiento y la Zanja $\mathrm{C}$ en la zona Norte del mismo.

Todas las cotas y medidas de profundidad fueron establecidas mediante posicionamiento por GPS sobre la base de un punto 0 ubicado en la meseta superior con una altura de 146,04 metros s.n.d.m. Cuando la naturaleza del cerro hacía imposible la medición desde este punto 0 , se procedió al traslado del mismo mediante el establecimiento de puntos 0 relativos resultando el siguiente cuadro de cotas absolutas:

\begin{tabular}{|c|c|}
\hline Sondeo & Cota (s.n.d.m.) \\
\hline $\mathrm{A} / 2$ & 140,85 \\
\hline $\mathrm{A} / 1$ & 146,15 \\
\hline $\mathrm{B}$ & 144,42 \\
\hline $\mathrm{K}$ & 146,13 \\
\hline $\mathrm{L}$ & 146,13 \\
\hline $\mathrm{M}$ & 146,67 \\
\hline $\mathrm{N}$ & 146,19 \\
\hline$\tilde{N}$ & 146,19 \\
\hline $\mathrm{O}$ & 146,47 \\
\hline $\mathrm{P}$ & 145,94 \\
\hline Punto 0 & 146,04 \\
\hline
\end{tabular}

2 Queremos manifestar nuestro agradecimiento por la labor realizada a los licenciados en Historia D. Marco Thiene (DEA), Dñ. ${ }^{a}$ Myriam López Domínguez (DEA) y D. Rafael Dorado Cantero así como a los estudiantes D. Tomás Agustín Reina Narváez, D. Antonio Pérez Narváez, D. Javier Gámez Segura y D. Juan Pedro Sánchez Sánchez. Los dibujos de plantas han sido realizados por D. Francisco Anguita Villar y los de perfiles, composición y digitalización por D. Salvador Bravo Jiménez. Por último, de la documentación gráfica se ha ocupado D. Miguel Vila Oblitas. Especial gratitud merecen D. Ildefonso Navarro Luengo y Dña Carmen Pérez, Director y Restauradora respectivamente del Museo Municipal de Estepona. 
El Sondeo K, ubicado en la zona Oeste de la meseta superior se conformó como un cuadrado de $4 \times 4$ metros con una superficie total de excavación de 16 $\mathrm{m}^{2}$. En total se han excavado 21 Unidades Estratigráficas.

El Sondeo L, ubicado al igual que el anterior en la zona Oeste de la meseta superior, se planteó como un rectángulo de $8 \times 4$ con una superficie total de excavación de $32 \mathrm{~m}^{2}$ aunque por las especiales características tanto orográficas como estratigráficas del mismo, se hizo necesaria una ampliación, replanteando el mismo 4 metros al Este conformándose por tanto un cuadrado final de $8 \times 8$ con una superficie total de excavación de $64 \mathrm{~m}^{2}$. En total se han excavado 54 Unidades Estratigráficas.

El Sondeo M viene situado también al Oeste de la meseta superior, constituyéndose como un rectángulo de $4 \times 7$ metros con una superficie total de excavación de $28 \mathrm{~m}^{2}$. En total se han excavado 11 Unidades Estratigráficas.

El Sondeo $\mathrm{N}$ viene ubicado en la zona Norte de la meseta superior. Se planteó como un rectángulo de $4 \times 3$ metros con una superficie total de excavación de 12 $\mathrm{m}^{2}$. Se decaparon un total de 8 Unidades Estratigráficas.

El Sondeo Ñ viene ubicado en la zona Este de la meseta superior. Se planteó como un rectángulo de $6 \times 2$ metros con una superficie total de excavación de 12 $\mathrm{m}^{2}$. Se decaparon un total de 20 Unidades Estratigráficas.

EI Sondeo O viene ubicado igualmente en la zona Este de la meseta superior. Se planteó como un rectángulo de $5 \times 3$ metros con una superficie total de excavación de $15 \mathrm{~m}^{2}$. Dadas las características especiales del mismo y su situación con respecto a la meseta superior, se decidió realizar varias ampliaciones del mismo con tendencia al Este conformándose al final una figura en forma de $L$ cuyo lado largo tenía 17 metros y la base 6 metros con una superficie total de excavación de $102 \mathrm{~m}^{2}$. Se decaparon un total de 40 Unidades Estratigráficas.

El Sondeo P se sitúa en la parte Este de la meseta superior aunque ligeramente escorado hacia el Sureste. Se planteó como un rectángulo de $8 \times 2$ metros con una superficie total de excavación de $16 \mathrm{~m}^{2}$. Se decaparon un total de 17 Unidades Estratigráficas.

Por lo que se refiere a las Zanjas, la llamada Zanja A es, con diferencia la más grande debido a su especial situación dentro del conjunto del yacimiento. Se planteó en la ladera Sur del mismo, la más afectada por el proyecto constructivo. Debido a la importancia de la zona para el posterior diagnóstico arqueológico y con el objetivo de abarcar la máxima cantidad de ladera, se procedió a compartimentar la propia zanja en tres transects separados por testigos aleatorios.

La llamada Zanja $A / 1$ se conformó como un rectángulo de $9 \times 2$ metros con una superficie total de excavación de $18 \mathrm{~m}^{2}$. Se decaparon un total de 10 Unidades Estratigráficas.

La Zanja A/2, continuación de la anterior en sentido Sureste es la más grande formando un rectángulo de $22,5 \times 2$ metros con una superficie total de excavación 


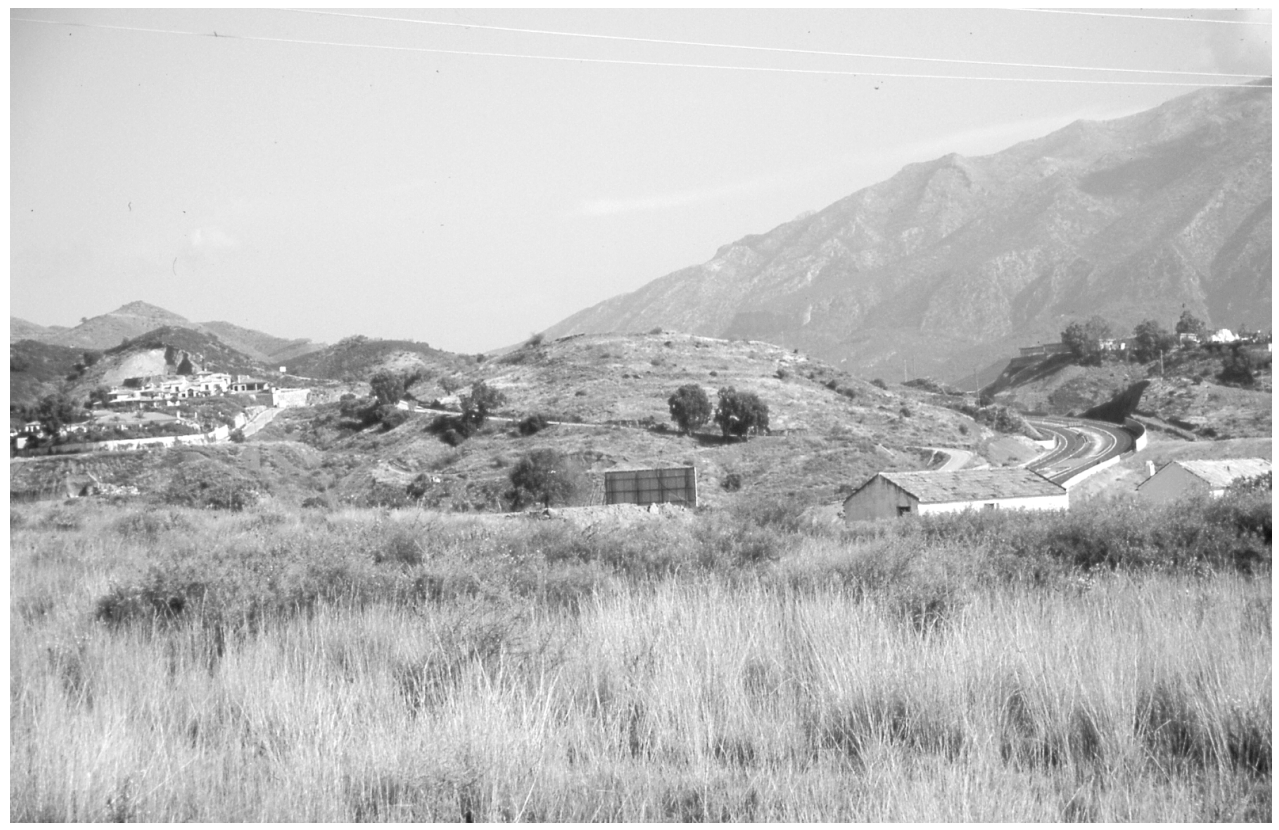

Fig. 2. Vista general del asentamiento.

de $45 \mathrm{~m}^{2}$. Se dejó un testigo entre $\mathrm{A} / 1$ y A/2 de 7 metros. Se decaparon un total de 33 Unidades Estratigráficas.

La Zanja A/3 continuación de la anterior en sentido Sureste conformó un rectángulo de $7 \times 2$ metros con una superficie total de excavación de $14 \mathrm{~m}^{2}$. Se dejó un testigo entre $A / 2$ y A/3 de 12 metros. Se decaparon un total de 7 Unidades Estratigráficas.

La Zanja B ocupa la ladera Oeste del yacimiento. Se conformó como un rectángulo de $15 \times 2$ metros con una superficie total de excavación de $30 \mathrm{~m}^{2}$. Se decaparon un total de 7 Unidades Estratigráficas.

La Zanja $C$ se ubica en la zona Norte del cerro formando un rectángulo de $20 \times 2$ metros con una superficie total de excavación de $40 \mathrm{~m}^{2}$. Se decaparon un total de 5 Unidades Estratigráficas.

Por tanto, se abrieron un total de 7 sondeos con una superficie excavada de $250 \mathrm{~m}^{2}$ en los cuales se decaparon 171 Unidades Estratigráficas, tanto sedimentarias como constructivas o interfaciales. Las tres zanjas han dado como resultado un total de superficie excavada de $147 \mathrm{~m}^{2}$ en los que se documentaron 62 Unidades Estratigráficas. Por tanto, el volumen total de superficie excavada en el yacimiento ha sido de $397 \mathrm{~m}^{2}$ y el total de Unidades Estratigráficas documentadas de 233. Dicha cantidad parece haber sido suficiente para delimitar y llevar a cabo un diagnóstico arqueológico del yacimiento, al menos en la meseta superior y en las laderas Oeste, Norte y Este. 


\section{PERIODIZACIÓN DEL YACIMIENTO}

La superposición física de unidades estratigráficas responde a un claro sistema de periodos de ocupación del yacimiento que, estudiados en el Sondeo $L$ y en la Zanja A/2, nos permiten establecer una dinámica general para la ocupación histórica del cerro.

A lo largo de esta campaña se ha logrado delimitar cronológicamente el yacimiento tanto en sus inicios (mediados del siglo iv a.n.e.) como en su abandono (alrededor de la década de los 80 a.n.e.).

\section{Periodo IV. Contemporáneo}

Ocupa la cubierta vegetal del actual solar. Destacan gran cantidad de materiales cerámicos de diversas épocas, aunque predominando los de época romana republicana y púnica mezclados con vidrios, plásticos, loza, etc producto de la remoción del terreno llevada a cabo por los trabajos de uso agrícola que se han sucedido en el cerro hasta prácticamente la actualidad.

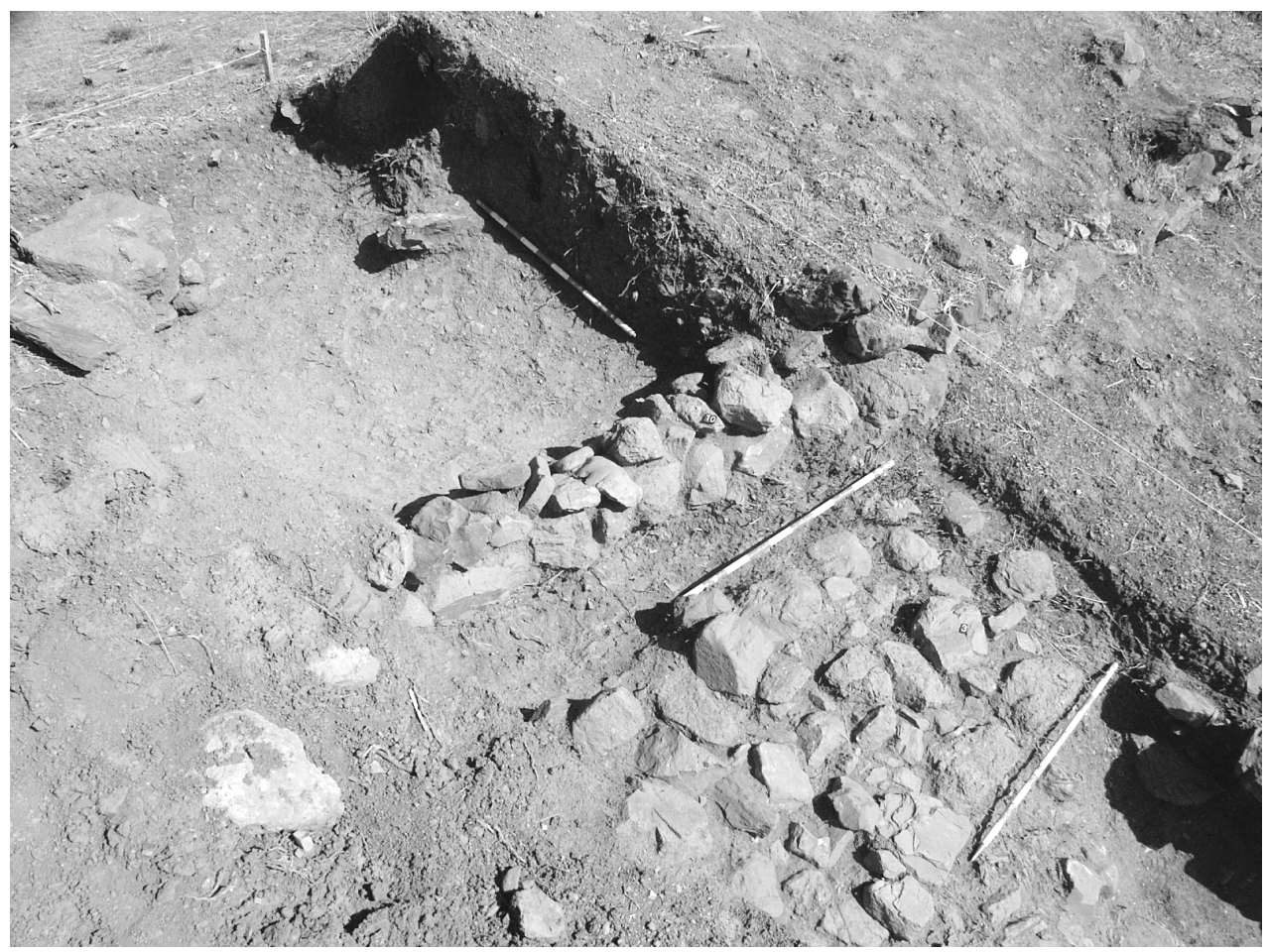

Fig. 3. Abancalamiento contemporáneo junto a estructuras antiguas. 
Destaca entre ellos una serie de líneas de abancalamiento para el cultivo de olivar del que quedan rastros todavía en la actualidad conformando una serie de líneas concéntricas que van recorriendo el perímetro del cerro a distintas alturas. A veces estos mismos bancales apoyan en estructuras más antiguas por lo que es más que probable que durante su construcción, estas estructuras eran parcialmente visibles.

\section{Periodo III (Romano - Republicano): (206 a 80 a.n.e. (circa))}

El Periodo que nos ocupa viene caracterizado por la acción antrópica desarrollada como resultado de los trabajos de acondicionamiento del cerro en 1999. Durante los mismos se acometieron labores de movimientos de tierras que produjeron una acusada afección a los niveles arqueológicos pertenecientes a este periodo. Estamos en grado de sostener que la práctica totalidad del asentamiento de época romana ha desaparecido con motivo de dichos trabajos. No obstante, la ocupación del solar tampoco parece caracterizarse por una ocupación intensiva. Han sido detectadas estructuras de dicho periodo en los sondeos $L, \tilde{N}, P$ y en las Zanjas A/1 y A/2. Todas parecen caracterizarse por pertenecer a cimentaciones de ambientes domésticos. Del Sondeo L destacamos las UU.EE 12004 y 12012.

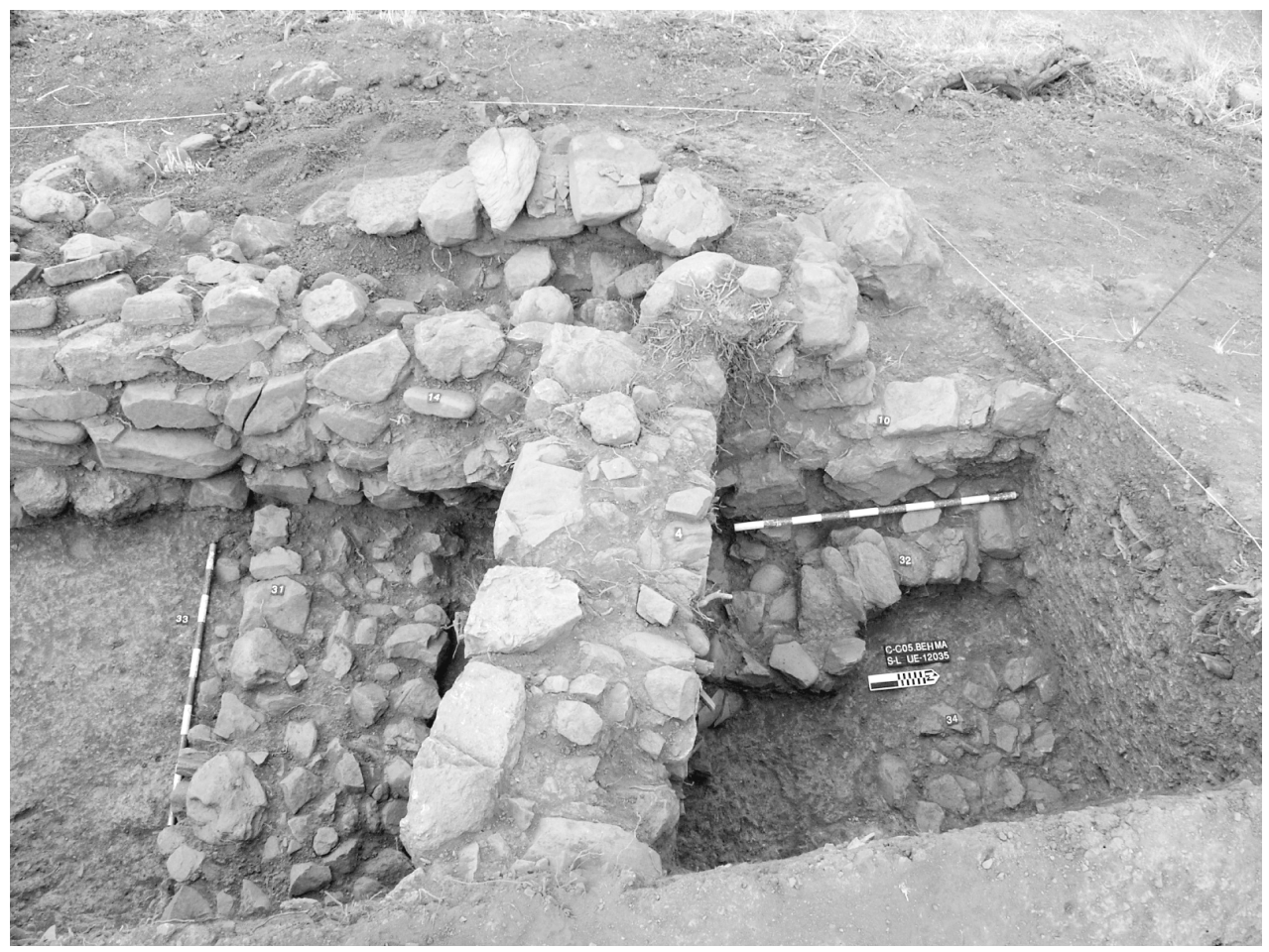

Fig. 4. Sondeo L. Superposición de cimentaciones romanas sobre la muralla púnica. 
Ambas se conforman como cimentaciones de muros con sentido SE-NW aunque aparentemente no pertenecen a la misma estructura. La destrucción de la estratigrafía (más de 5 metros de potencia estratigráfica desde la cota superior del Cerro 150 m.s.n.m hasta la cota del Sondeo a 146,13 m.s.n.m.) referida a estos niveles de ocupación romana hace imposible determinar la funcionalidad de ambos muros. No obstante, las UU.EE. 12002 y 12003/12049 interpretadas como un vertido de nivelación fechado por ánforas T. 7.4.3.3, ánforas Grecoitálicas del tipo Benoit 2, imitaciones en barro local de platos de pescado Lamb. 23 así como barnices negros campanos del tipo A (amorfos) hace que nos llevemos la fecha de construcción de estas estructuras a momentos en torno a los inicios del siglo II a.n.e.

La presencia de tipos relacionables con producciones campanas antiguas (220 a.n.e. inicio) y medias clásicas (180 hasta 100 a.n.e.) hace decantarnos por una cronología antigua para la construcción de dichas cimentaciones en torno a los momentos iniciales del siglo II a.n.e. El hallazgo de un fragmento de pie de Lamb. 23 refuerza este razonamiento toda vez que parece atestiguada la desaparición de este tipo cerámico durante la segunda mitad del siglo II a.n.e. (Roca, M., 2005; 30). Dichas U.EE 12004 y 12012 a las que habría que sumar otro muro decapado parcialmente en el perfil Sur del Sondeo $L$ cortan a UU.EE sedimentarias pertenecientes al periodo anterior, en concreto a 12007 y sus equivalentes $12008 \mathrm{~A}$ y 12008 B, 12011 A y sus equivalentes 12011 B, 12016 y 12015. A su vez, la UE 12004 rompe a la muralla de época púnica $12014 / 12010 / 12019 / 12018$ por su lado Norte. La cimentación UE 12012 es más potente, cortando niveles deposicionales no solo del periodo púnico sino que llega a alterar a niveles del periodo mastieno llegando a apoyar directamente sobre muros de éste periodo (UU.EE 12039 y 12040) y rompiendo a la muralla púnica por su lado Sur.

Por tanto y a tenor de la información elaborada en este Sondeo, todo parece indicar que la primera presencia romana lleva a cabo una reestructuración del cerro en la cual no se tiene en cuenta el urbanismo del asentamiento de época púnica respondiendo a patrones urbanísticos de otro tipo aunque debido al grado fragmentario de la información recuperada, se nos hace del todo imposible elaborar una hipótesis factible sobre la funcionalidad de dichas estructuras.

Del Sondeo Ñ proviene una estructura muraria similar a las excavadas en el Sondeo L; se trata de la UE-15003 cuya orientación y parámetros constructivos es similar a las del Sondeo L. Dicho muro, el cual discurre en sentido W - E, corta a una estructura muraria de época anterior (UEs 15014/15016) que ya se encontraba arruinada cuando se construyó la citada UE-15003. Debemos adscribirla igualmente a los momentos iniciales de ocupación romana del asentamiento aunque la escasez de hallazgos claramente estratificados impide una adscripción segura. No obstante su orientación, factura y ubicación espacial (similar cota a las estructuras romanas del Sondeo $L$ ) hace que la ubiquemos cronológicamente en los momentos iniciales de la ocupación romana del cerro.

En la ladera Sur del yacimiento, en la llamada Zanja A/1 se excavó la esquina de una habitación fechada merced a hallazgos de Campaniense $A$ antigua a inicios del siglo II a.n.e. Se trata de la esquina formada por las UU.EE 18008 y 18009. Di- 


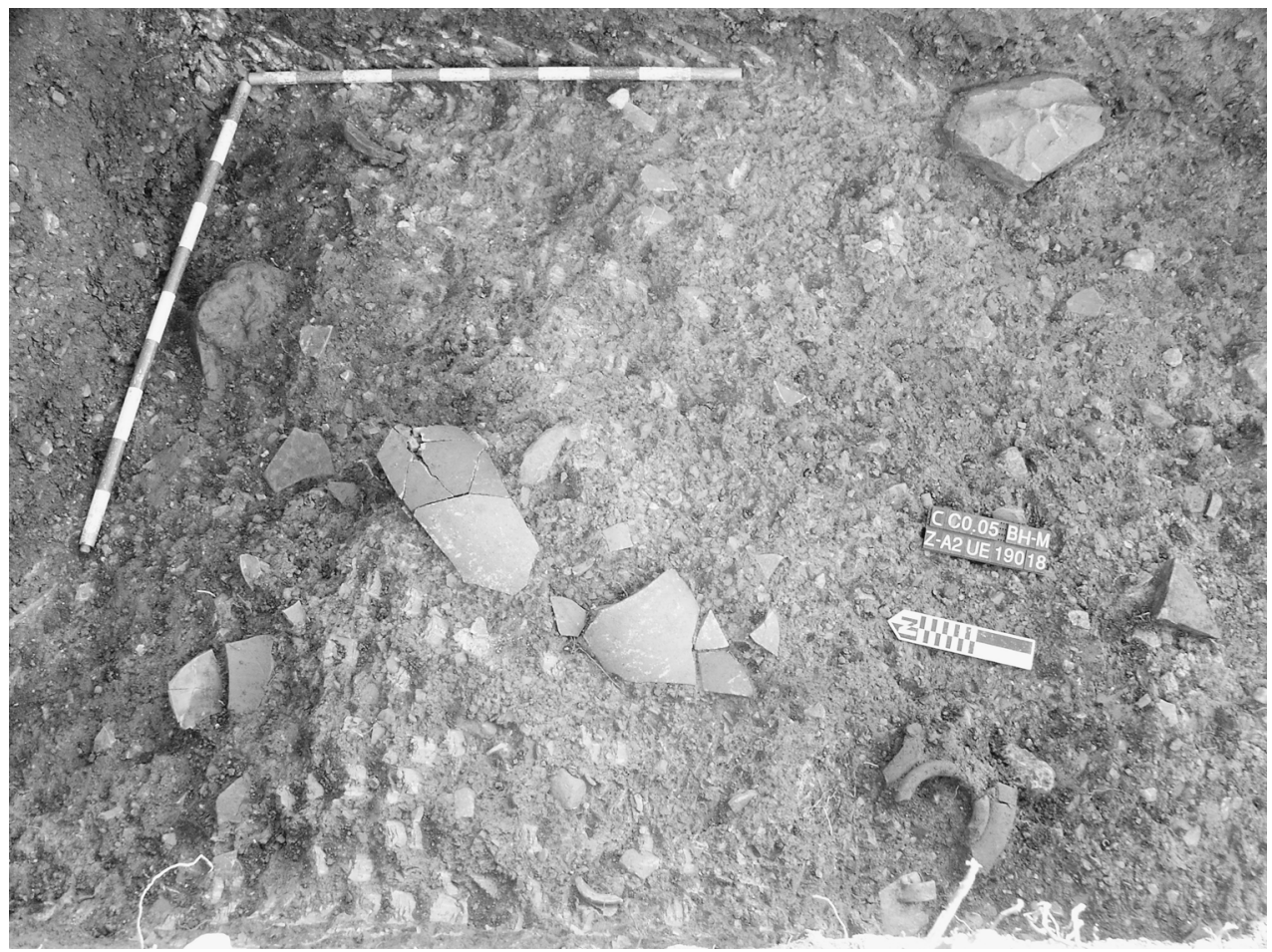

Fig. 5. Sondeo A/2. Vertido de nivelación para suelo de época romano republicana.

cha estancia está colmatada por un nivel sedimentario (UE-18006) que fecharíamos en estas fechas gracias al hallazgo de cubiletes de paredes finas y Campaniense $\mathrm{A}$ antigua además de imitaciones de campanienses en barro local.

Dicha construcción viene parcialmente cortada por una nueva esquina formada por las UU.EE 18005 y 18003 que fechamos hacia el año 100 o primeros decenios del siglo I a.n.e. merced a la recuperación de algunos fragmentos de barnices negros campanos del tipo A media clásica y el hallazgo de un ejemplar de imitación de un cubilete Lamb. 2. Dicho tipo se fabrica solamente en Campaniense $B$ aunque es de los primeros ejemplares conocidos de Campaniense B del tipo etrusco que viene fechado a mediados del siglo II a.n.e. Es de los pocos ejemplos de Campaniense B recuperados durante la Actividad Arqueológica por lo que estimamos que el fin de la ocupación romana tuvo lugar en estas fechas.

Por último, en la Zanja A/2 hemos detectado la preparación para la construcción de una estructura arquitectónica mediante la preparación de un suelo por medio de un vertido de nivelación UE 19018 cuya matriz presenta numerosas inclusiones de cerámicas, huesos y carbones. Dicha Unidad Estratigráfica ha sido interpretada como un vertido de nivelación amortizando estructuras anteriores que analizaremos más adelante y que no corresponden con este periodo. Des- 
graciadamente no sabemos si dicho vertido se realizó para nivelación de suelo o de estructuras arquitectónicas toda vez que las características orogénicas de la zona (fuerte pendiente hacia el Sur) y la erosión natural han lavado totalmente las hipotéticas estructuras que eran soportadas por dicho vertido de nivelación. Por los materiales (ánforas T 7.4.2.1, ibero púnicas, campanienses A, cerámica pintada, fusaiolas, etc) hemos adscrito cronológicamente dicha nivelación a la Fase I del Periodo romano republicano y dada la cercanía a la Zanja A/1 propondríamos su relación con la estructura formada por las UU.EE 18008 y 18009.

Así, el Periodo romano - republicano viene conformado por dos fases de ocupación: la más antigua denominada Fase I estaría caracterizada por una fuerte remodelación urbanística de la ciudad púnica recién conquistada cuyos ejes vienen cambiados totalmente. Se iniciaría inmediatamente tras la conquista del asentamiento en el año 207 a.n.e. y abarcaría todo el siglo II a.n.e.

La Fase II de este periodo solamente la hemos detectado en la Zanja A/1 y se caracterizaría por una nueva remodelación urbanística (al menos en la zona Sur) construyendo una estructura que apoya en parte en anteriores romanas. No podemos determinar el inicio de esta Fase II aunque la UE 18006 que amortiza la estructura de la Fase II A debe fecharse a mediados del siglo II a.n.e. Por tanto, dicha Fase II se iniciaría hacia mediados o el último tercio del siglo II a.n.e. hasta el abandono del Cerro en torno a la década de los años 80 a.n.e.

\section{Periodo II (Púnico - Cartaginés): (237 a 206 a.n.e.)}

Es indudablemente el Periodo que más datos ha aportado tanto desde el punto de vista cronológico como a nivel de estructuras y de registro material. Todo esto nos ha permitido elaborar una estratigrafía con elementos datantes de gran precisión cronológica que, aunque referidos al Sondeo L, nos sirve de modelo para lo que debió ser la vida en el cerro durante este Periodo.

Prácticamente lo hemos detectado en todos los sondeos lo cual prueba su conservación y su importancia. Evidentemente ha sido parcialmente transformado por las acciones constructivas romano republicanas aunque estas también han ayudado en parte a su conservación.

Se ha conseguido establecer dos fases dentro de este Periodo; fases que solamente detectamos en el Sondeo $L$ pero que entendemos que son de gran importancia para conocer el desarrollo histórico de la ocupación poblacional de Cerro Colorado desde mediados del siglo III hasta el año 207 a.n.e.

La Fase I, más antigua, la hemos fechado el año 237 a.n.e. para su inicio. Coincide con la ocupación cartaginesa de la zona de manos de Amilcar Barca. Se caracteriza por la construcción de una muralla de mampuestos irregulares de mediano a gran tamaño y con una anchura irregular pero que llega a 1,75 metros. Dicha estructura ha sido detectada al Sur del Cerro en la Zanja A/2 (UE 19015) y en la meseta superior, en la zona Este del Cerro en el Sondeo L (UU.EE 12014, 


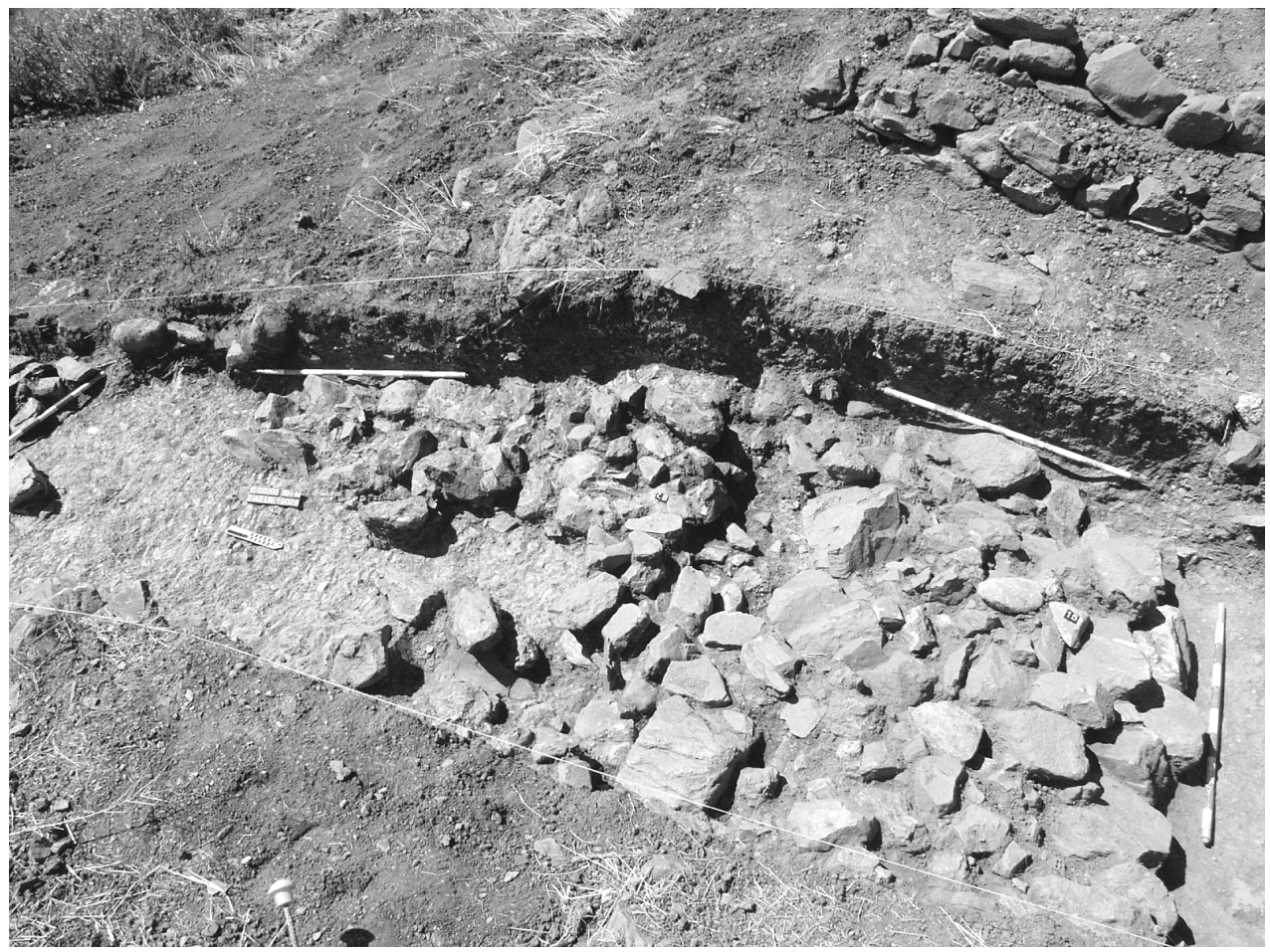

Fig. 6. Sondeo A/2. Muralla púnica en su vertiente Sur.

$12019,12018)$. En este último Sondeo hemos podido delimitar la estructura constructiva de la muralla, la cual queda conformada por dos ejes o líneas de encofre formadas por mampuestos careados al exterior (a modo de un opus pseudo vittatum) con ligante basándose en barro local. El interior viene relleno con mampuestos de mediano tamaño alojados a hueso sin ningún tipo de ligante. No hemos detectado la presencia de estructuras que partan de la muralla a modo de casamatas o habitaciones asociadas a ella. Es de reseñar, no obstante, que en el Sondeo L discurre una estructura muraria paralela a la anterior (UE12052) conformando un pasillo de unos 3 metros de anchura que no podemos precisar si se trataría de una calle o espacio para deambulatorio o si formaba parte de la estructura defensiva del asentamiento. Nos decantamos por la primera opción ya que en la Zanja A/2 no hemos visto similar asociación y por la cercanía a lo que hemos considerado como vano de ingreso al recinto lo cual explicaría la ubicación de dicha calle. Por último, la aparición de un suelo de cal UE 12054 entre ambas estructuras hace que nos decantemos por una sola cinta muraria, la conformada por las UU.EE 12014/12019/12018. Esta muralla, cuyo recorrido es posible seguir en parte y al nivel de cimentación por la zona Este del yacimiento, ha sido destruida parcialmente por la construcción de un camino en época contemporánea. Sus restos los hemos podido excavar parcialmente en la Zanja B (UE 20003) cuyos 


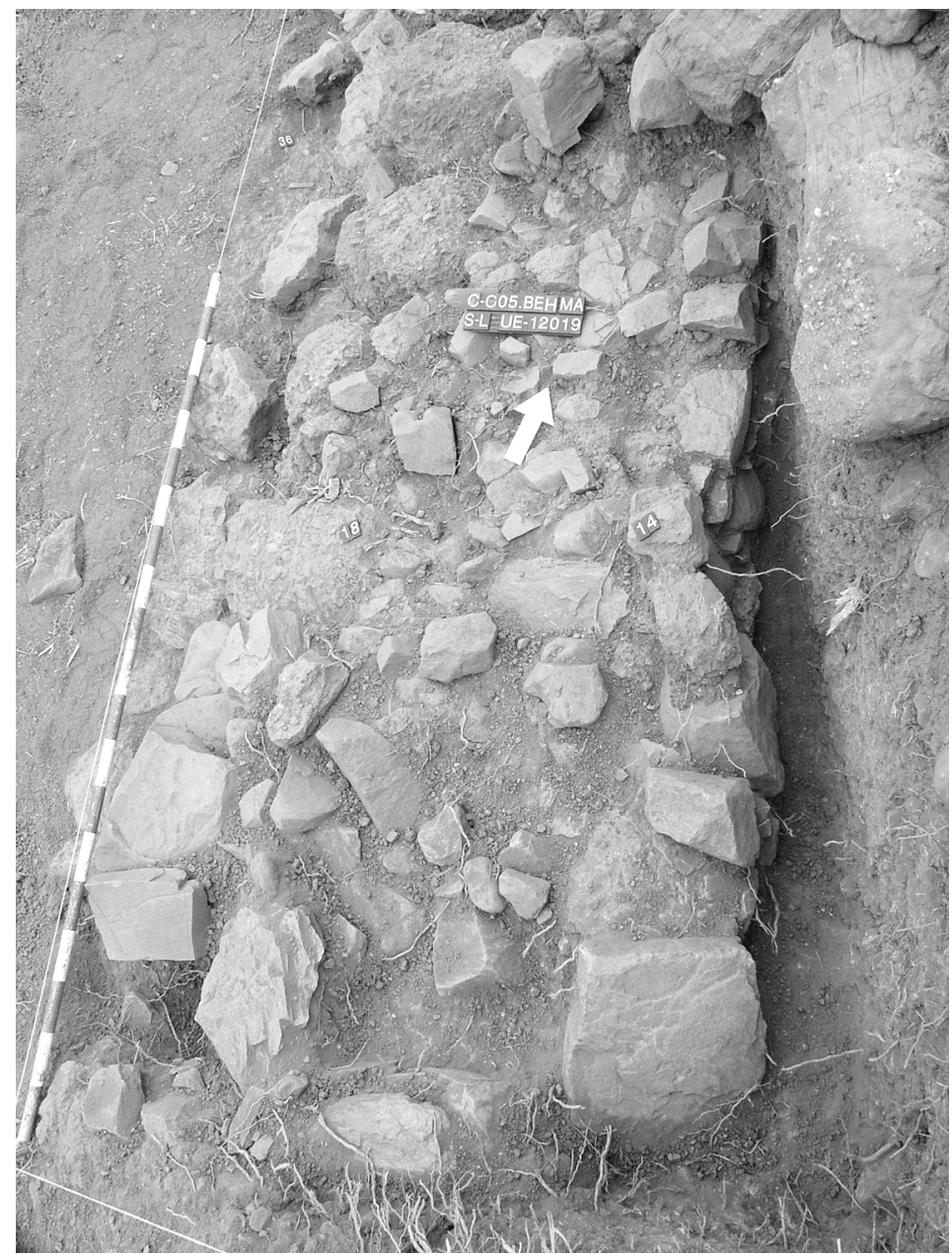

Fig. 7. Muralla púnica en su vertiente Oeste. Se aprecia la técnica constructiva.

mampuestos cayeron arrastrados tras su arrasamiento directamente en sustrato geológico.

Continuando el recorrido natural de esta estructura defensiva, la excavación del Sondeo $\mathrm{M}$ ha proporcionado la aparición de tres estructuras que discurren en sentido SE - NW y que probablemente adosen (al menos la UE-13009) a dicha muralla. El Sondeo $\mathrm{M}$ es importante por la aparición de lo que hemos interpretado como vano abierto en esta estructura defensiva. Se conforma por dos líneas de muros (UU.EE 13004 y 13010) que discurren paralelas entre ellas con una distancia de 3,5 metros sirviendo de suelo el propio sustrato geológico aunque rebajado y acondicionado a modo de calle o camino (UE-13008). Son estructuras que presentan un careo excepcional a base de mampuestos de mediano a gran tama- 
ño perfectamente careados al exterior con un ángulo de buzamiento hacia el Norte de 40 centímetros.

A esta Fase I hemos adscrito también una estructura con similares parámetros constructivos que discurre en dirección SW - NE en la parte Este del Cerro excavada en el Sondeo $\tilde{N}$. Se trataría de parte de la muralla púnica formada por las UU.EE 15014/15016. Dichos restos murarios en las zonas Sur, Oeste y Este del cerro proponen un asentamiento cercado por una muralla tipo oppidum lo cual es muy común en la zona a partir de mediados del siglo iv a.n.e. No obstante, estamos en grado de precisar la fecha de construcción de esta cerca merced al hallazgo en el suelo de construcción / ocupación (UE-12021) de la citada estructura de tres ejemplares de ánforas T. 12.1.1.1 que fechan perfectamente la ocupación del suelo en el último tercio del siglo III a.n.e. coincidiendo con la ocupación bárquida de la zona. Relacionada con la muralla se nos presenta una substracción de forma rectangular (UE-12023) que discurre perpendicular a la muralla y que probablemente sirviera para encajar algún tipo de estructura de madera asociada a la muralla.

A la Fase I también podemos asociar una estructura de planta cuadrangular conformada por las UU.EE 16026/16028/16019/16033 cuyo vano se situaría en dirección SE y del que se ha conseguido documentar varias remodelaciones de su

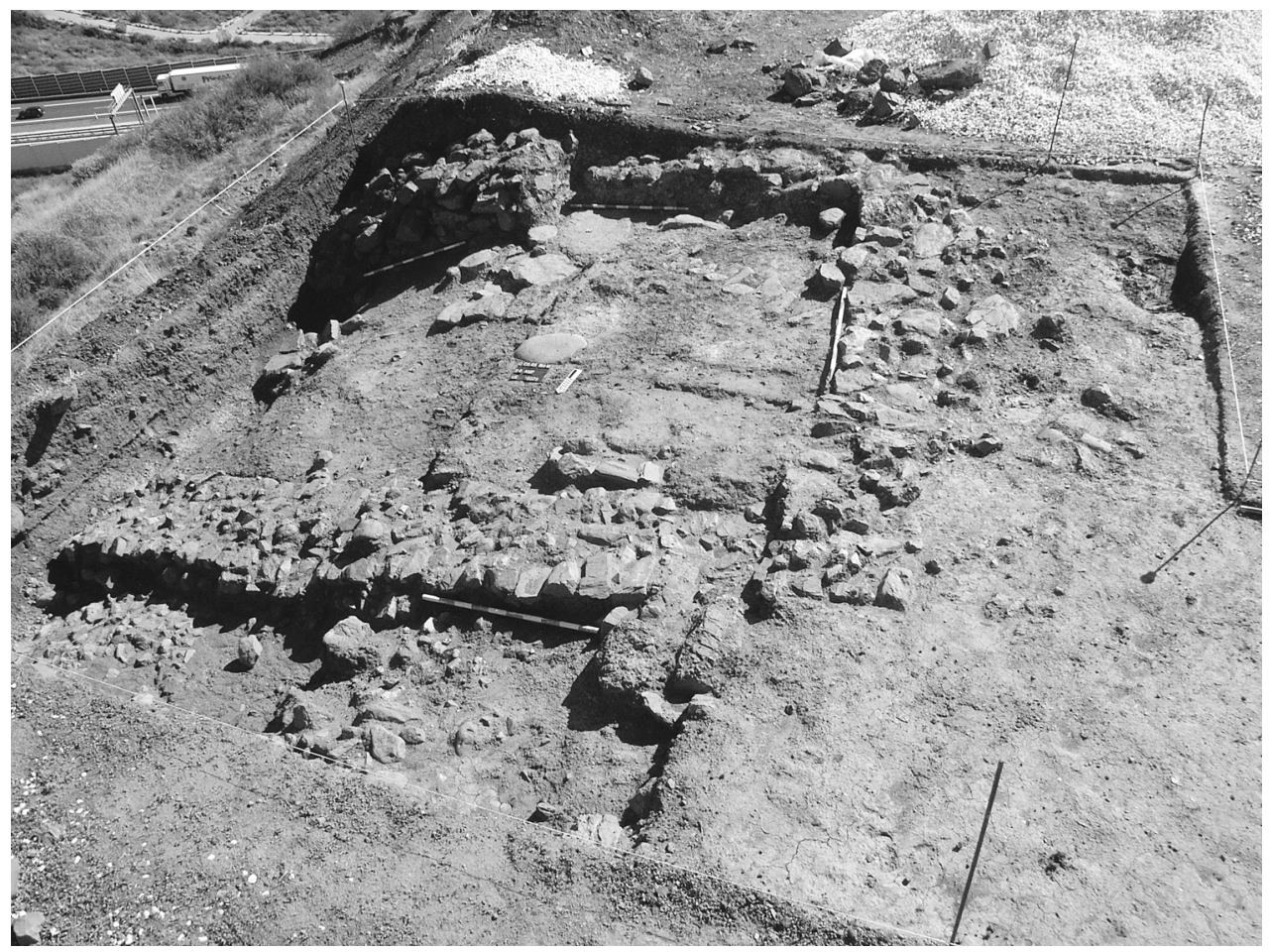

Fig. 8. Edificio del Sondeo O. 
suelo. Dicha estructura parece que tuvo una fuerte pervivencia toda vez que sufre importantes remodelaciones con superposición de varios pavimentos. Reposa sobre el substrato geológico en el cual excava parcialmente sus cimientos. El interior está pavimentado con grandes losas de piedra local (UE-16022). Dicho interior va a sufrir continuas remodelaciones mediante la colocación de nuevos suelos de cal o tierra apisonada (UU.EE 16013, 16014).

Destacamos también como perteneciente a esta Fase I la construcción y uso de un muro de mampuestos irregulares de mediano tamaño (UE-11011) aunque sus proporciones son tan reducidas que resulta casi imposible aproximarse a su funcionalidad.

Destacamos de la Zanja A/2 un muro de buena factura que discurre en dirección NE-SW (UE-19013) al que viene asociado un derrumbe de tapial (UE-19032) desconocido en el yacimiento. Dichas UU.EE están totalmente amortizadas por el vertido de nivelación romano UE 19018 lo cual indica las continuas remodelaciones urbanísticas que sufrió el asentamiento.

Continuando en la Zanja $A / 2$, se ha podido excavar una estructura cuadrangular de similar técnica constructiva a las de la Fase I de este periodo caracterizada por la buena calidad en la confección del opus quasi vittattum. La forman las UU.EE 19019/19020/19021 a las que se asocia un suelo UE-19026 con un hogar en su interior (UE-19024). Presenta similar orientación que el muro situado más al Norte (UE-19031) lo cual induce a pensar en construcciones de tipo aterrazado, muy común en la propia Cartago y en los poblados de su ámbito.

De esta Fase I documentamos también dos estructuras (UU.EE 19016 y 19017) que discurren perpendiculares a la muralla UE 19015 y que, en el caso de la UE 19017 podría adosarse lo cual cabría la posibilidad de poder interpretarse como una casamata.

En momentos indeterminados pero que muy bien como luego veremos podrían datarse hacia el año 216 a.n.e., se inaugura la que hemos llamado Fase II caracterizada por la ruina parcial de la muralla cuyos derrumbes constatamos en las UU.EE 19028, 12006, 15017, 15011 y del edificio cuadrangular excavado en el Sondeo O (UE 16026). También vemos trazas de esta ruina de las estructuras de la Fase I en las UU.EE 19022 y 19022 que se conformarían como derrumbes de la habitación formada por las UU.EE 19019/19020/19021. En el Sondeo K, la UE11012 se constituye igualmente como un derrumbe del muro UE-11011. En el Sondeo L, el cual muestra un abanico estratigráfico de todas las fases ocupacionales del yacimiento, dicha Fase II viene caracterizada por la llegada de una potente unidad estratigráfica sedimentaria, UE 12016/12011/12015 con muy poco material aunque caracterizada por una tierra arcillosa de color rojo intenso. Sobre ésta se deposita en todo el yacimiento una tierra de color marrón oscuro, UE 12008/12007 que podemos datar perfectamente en la primavera o el verano del año 207 a.n.e. merced al hallazgo de un ocultamiento compuesto por tres orzas con sus respectivas tapaderas llenas de joyas, recortes y gran cantidad de plata. Especial mención merece las monedas recuperadas en el hallazgo entre las cuales destacamos 


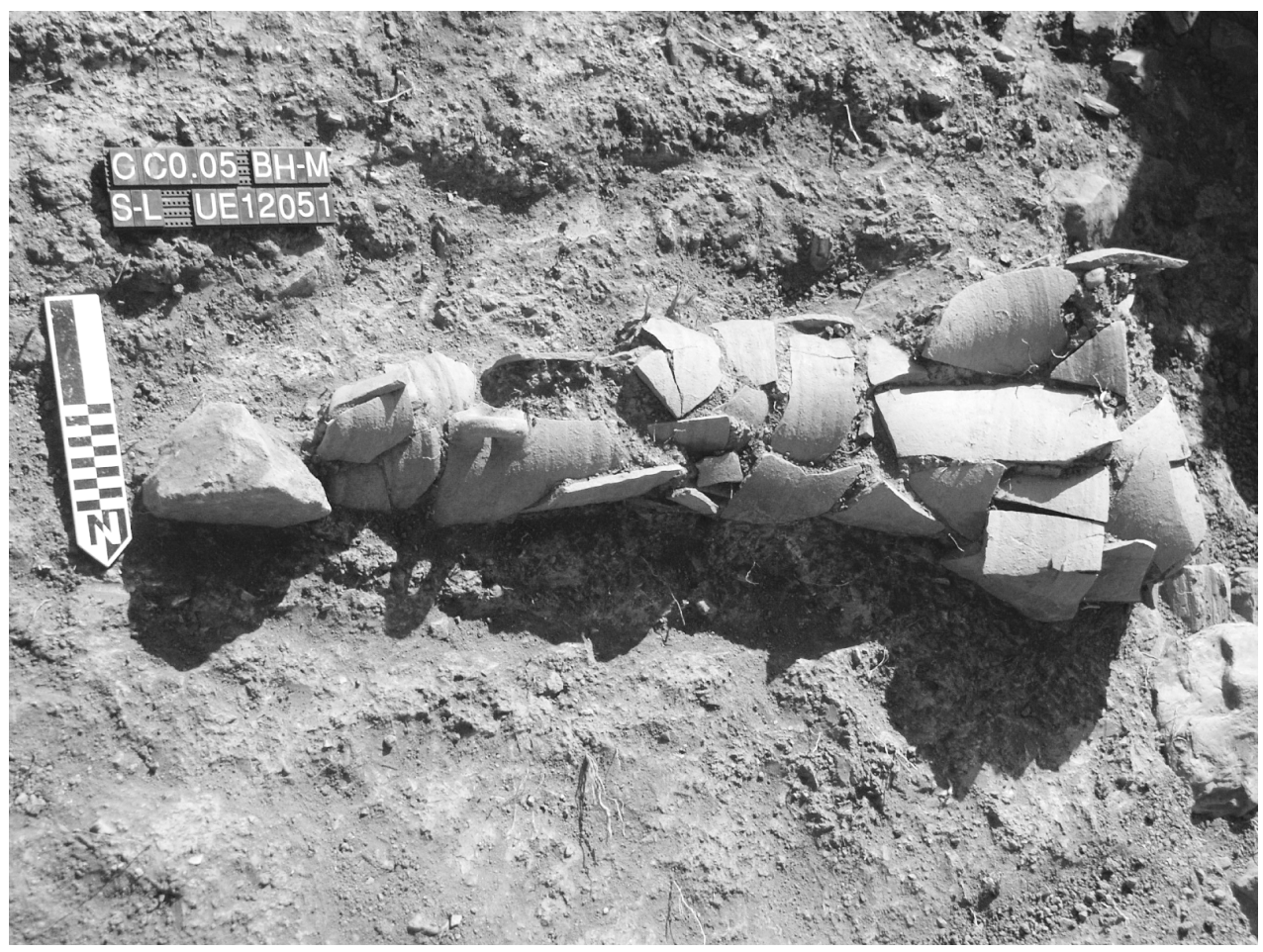

Fig. 9. Ánfora T.12.1.1.1 del Sondeo L.

las romano-campanas (cuadrigatos, bigatos y victoriatos) y las hispano cartaginesas. El nivel es poco consistente y quizás haya sido cortado o rebajado en su cota techo por los ingenieros romanos a la hora de construir las cimentaciones de la nueva ciudad. Lo cierto es que la situación del tesorillo (bajo un acebuche) hizo del todo imposible su excavación en planta por lo que abordamos la misma desde el perfil del testigo que dejó el árbol. Ante la magnitud y las características del hallazgo, se decidió desmontar el acebuche una vez retirado y documentado el hallazgo.

Los materiales que asociamos a esta Fase I son básicamente ánforas $\mathrm{T}$. 12.1.1.1 en relativo buen estado de conservación lo que quizás implique una salida precipitada del recinto. La existencia del tesorillo y la gran cantidad de cerámicas en buen estado de conservación (cuencos y platos casi enteros además de las ánforas) hace pensar en esta posibilidad. No obstante, no hemos detectado ni destrucción en los elementos defensivos excavados, ni niveles de incendio, etc. Sí se ha constatado la presencia de elementos metálicos de carácter armamentístico tales como un soliferrum en el Sondeo O y una daga con pomo redondo en el Sondeo L.

Visto lo anterior, el Periodo Púnico se caracterizaría por la construcción de un gran recinto amurallado en su Fase II así como una amplia labor constructiva en la 


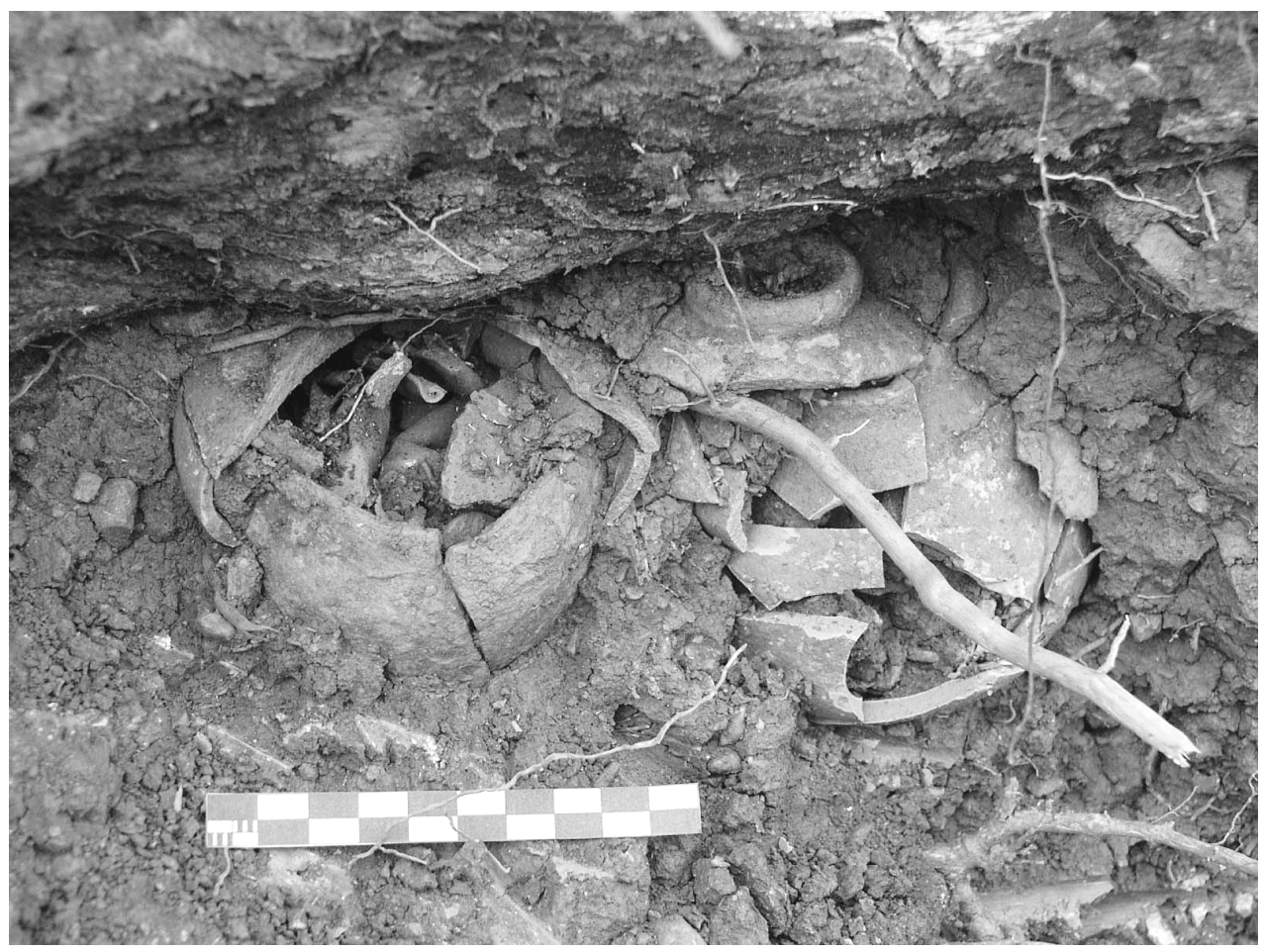

Fig. 10. Sondeo L. Tesorillo cartaginés en el momento de su hallazgo.

ciudad propiciada probablemente por la llegada de Amilcar Barca a la zona. Sus límites cronológicos abarcarían desde el año 237 hasta el 216 a.n.e.

A partir del año 216 a.n.e. y hasta el 207 a.n.e. se lleva a cabo una ruina y decadencia de las estructuras construidas durante la fase anterior con un rápido abandono del asentamiento aunque sin observarse trazas de violencia ni destrucción sistemática.

\section{Periodo I (Mastieno): (348 a 237 a.n.e.)}

El primer periodo ocupacional del cerro se caracteriza por la presencia de materiales que se fechan desde mediados del siglo IV a.n.e. como son barnices negros de ámbito ático y siciliota. Dichas cerámicas aparecen asociadas a estructuras que hemos detectado solamente en el Sondeo L. Podemos distinguir hasta un total de tres fases ocupacionales durante este Periodo. La más moderna denominada Fase III, estaría constituida por una serie de aportes sedimentarios (UU.EE 12026/12022(12025/12027) que pueden indicar el abandono de, al menos, esta parte del yacimiento. Dichos niveles se encuentran amortizando un suelo de uso de tierra apisonada y textura bastante compacta (UU.EE 12033/12037) al que se 
asocia un muro realizado con mampuestos irregulares de pequeño y mediano tamaño trabados con barro local (UU.EE 12031/12044 y UU.EE 12039 y 12047A) que daría paso a la denominada Fase II. Dichos muros discurren paralelos entre sí formando un espacio cuadrangular al que viene asociado el suelo UE $12033 / 12037$.

La Fase I más antigua y que se constituye como la primera ocupación humana del cerro la fechamos en sus inicios en torno al año 348 a.n.e. El substrato geológico (UE-12042) viene preparado mediante un vertido de piedra local (UE-12043) para nivelar la construcción un muro de mampuestos irregulares trabados con barro local (UU.EE 12040/12047) el cual es utilizado por el muro UU.EE 12039/12047 como cimentación. Similar proceso tiene lugar en la asociación entre el muro UU.EE 12038/12045 dando apoyo como cimentación al muro UU.EE 12031/12044. conformándose un espacio rectangular que será cortado por la construcción de muralla de la Fase I del Periodo púnico.

El hallazgo de una copa de barniz negro del tipo de labio interior marcado también denominada del grupo Viena 116 que se fecha en Occidente a mediados del siglo IV a.n.e. (Jiménez, J. y Ortega, J., 2004:169) amortizando el muro UE-12031 fecha perfectamente la construcción del mismo en torno al 350 a.n.e. Una pieza similar ha sido recuperada en la Zanja A/2 en niveles de relleno (UE-19005) y por

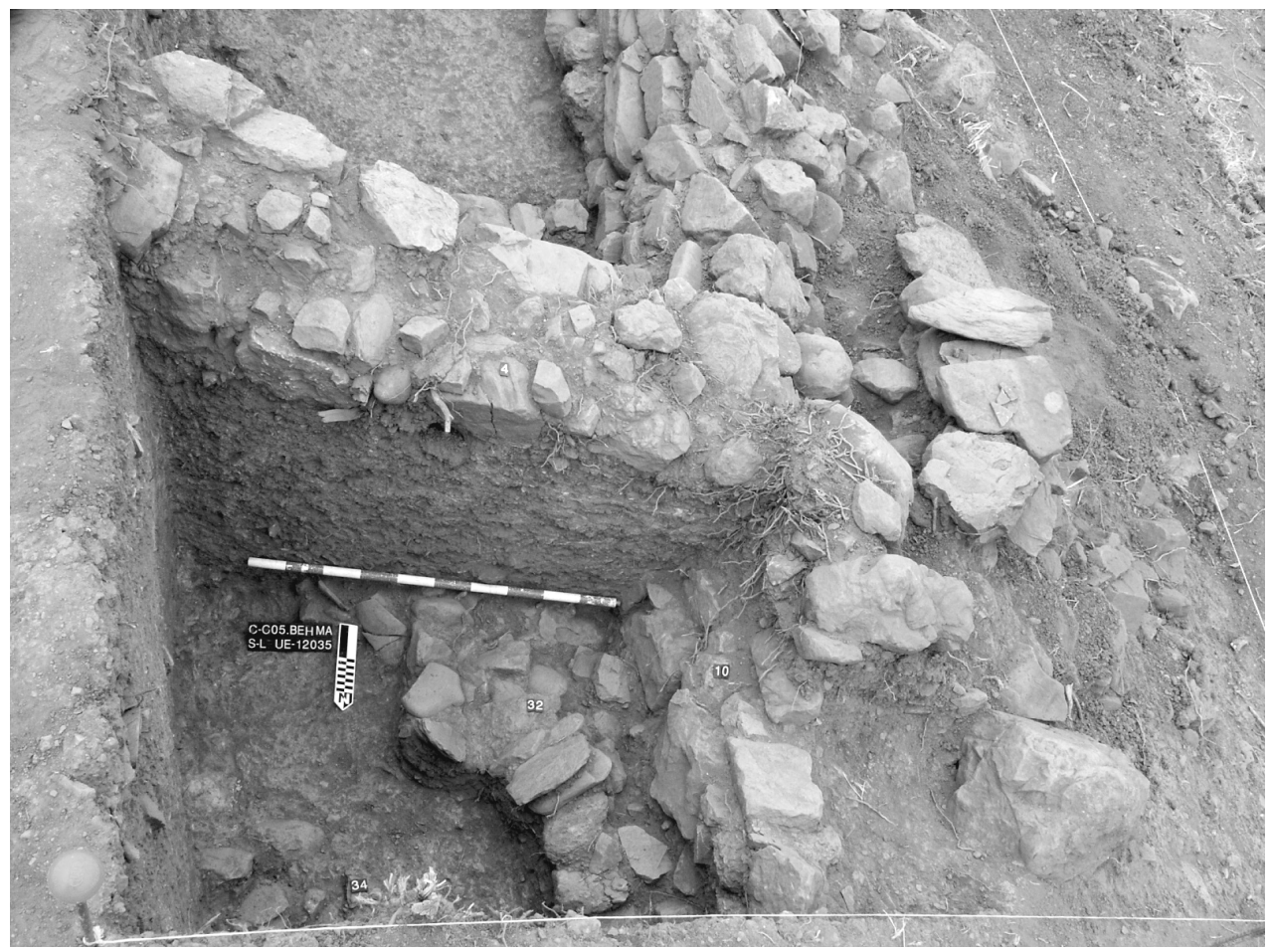

Fig. 11. Sondeo L. Estructuras mastienas amortizadas por la muralla púnica. 
tanto estratigraficamente descontextualizada lo cual prueba la presencia de esta fase en la zona Sur del yacimiento.

\section{INTERPRETACIÓN HISTÓRICA}

El año 348 a.n.e. tiene lugar un hecho singular que tendrá notables consecuencias para la zona que nos ocupa; según comenta Polibio ${ }^{3}$, los romanos y sus aliados y los cartagineses y sus aliados firman un tratado cuyo análisis no es objeto de este trabajo (Díaz, A., 1997: 263). No obstante, en dicha convención se nombra la ciudad de (Massia) Mastia. Dicha ciudad, capital del territorio habitado por los Mastienos/Mastianos/Mastetanos o Massienos es de enorme interés para el presente trabajo.

En efecto, son varios los testimonios que nos hablan de la ubicación en la zona adyacente al estrecho de Gibraltar del pueblo de los Mastienos. Hecateo de Mileto ${ }^{4}$ ya en el siglo vi a.n.e. menciona a los Mastienos como habitantes ${ }^{5}$ de la zona adyacente al estrecho de Gibraltar nombrando algunas de sus ciudades como son K $\alpha \lambda \alpha \theta \varepsilon$ (Calate), $\Sigma v \alpha \lambda \iota \omega$ (Sualis), M $\alpha 1 v o \beta \omega \rho \alpha$ (Menobora), $\Sigma v \zeta o \omega$ (Sixo) y Mo$\lambda v \beta \delta \vee \eta$ (Molibdine). Al menos dos de ellas, $\Sigma v \alpha \lambda \iota \omega$ y $\Sigma v \zeta o \omega$ pueden identificarse correctamente con las romanas Suel (Castillo de Fuengirola) y Sexi (Almuñecar) lo que probaría que desde el siglo vi a.n.e. tenemos poblaciones mastienas habitando la zona donde se ubica Cerro Colorado.

Hacia el siglo Iv a.n.e., el Pseudo-Escimno ${ }^{6}$, Herodoro ${ }^{7}$ y Teopompo describen la región del estrecho, ubicando la ciudad de $\Xi \varepsilon \rho$ (Jera) ${ }^{8}$ en sus inmediaciones y dándonos éste último el precioso dato de que la región se conoce como $M \alpha \sigma \sigma \int \alpha$ (Masía) $)^{9}$ :

Masía: región vecina de los tartesios. El término gentilicio es masiano

Polibio de Megalópolis será el autor que, años más tarde (a finales del siglo III a.n.e.) vuelva a ilustrarnos sobre Mastia ${ }^{10}$ y su región aunque esta vez dentro del tratado suscrito entre Cartago y Roma en 348 a.n.e. No obstante, en la Ora Marítima de Rufo Festo Avieno, puede encontrarse una fuente realmente antigua (hacia 520 a.n.e.) (Bravo, S., 2002: 141) que nos habla nuevamente de Mastia y los Mastienos destacando que viven al Este de las Columnas de Heracles coincidiendo, por tanto, con lo dicho por Hecateo y Herodoro (Koch, M. 2004: 188). Este territorio será el que luego aparecerá habitado (a tenor de las noticias dadas por los

\footnotetext{
3 Historia, III, 24,1.

4 THA, II A, 22. Pág. 142.

5 Fr. 41 Jacoby / (St. Byz.) apud THA, II A, 23. Pág. 142.

$6198 \mathrm{~s}$.

7 Fr. 2a Jacoby.

8 Philippica, FGH 115 F 199, apud THA, II. Pág. 465.

9 Philippica, FGH 115 F 200, apud THA, II. Pág. 465.

10 Ver nota no. 17.
} 


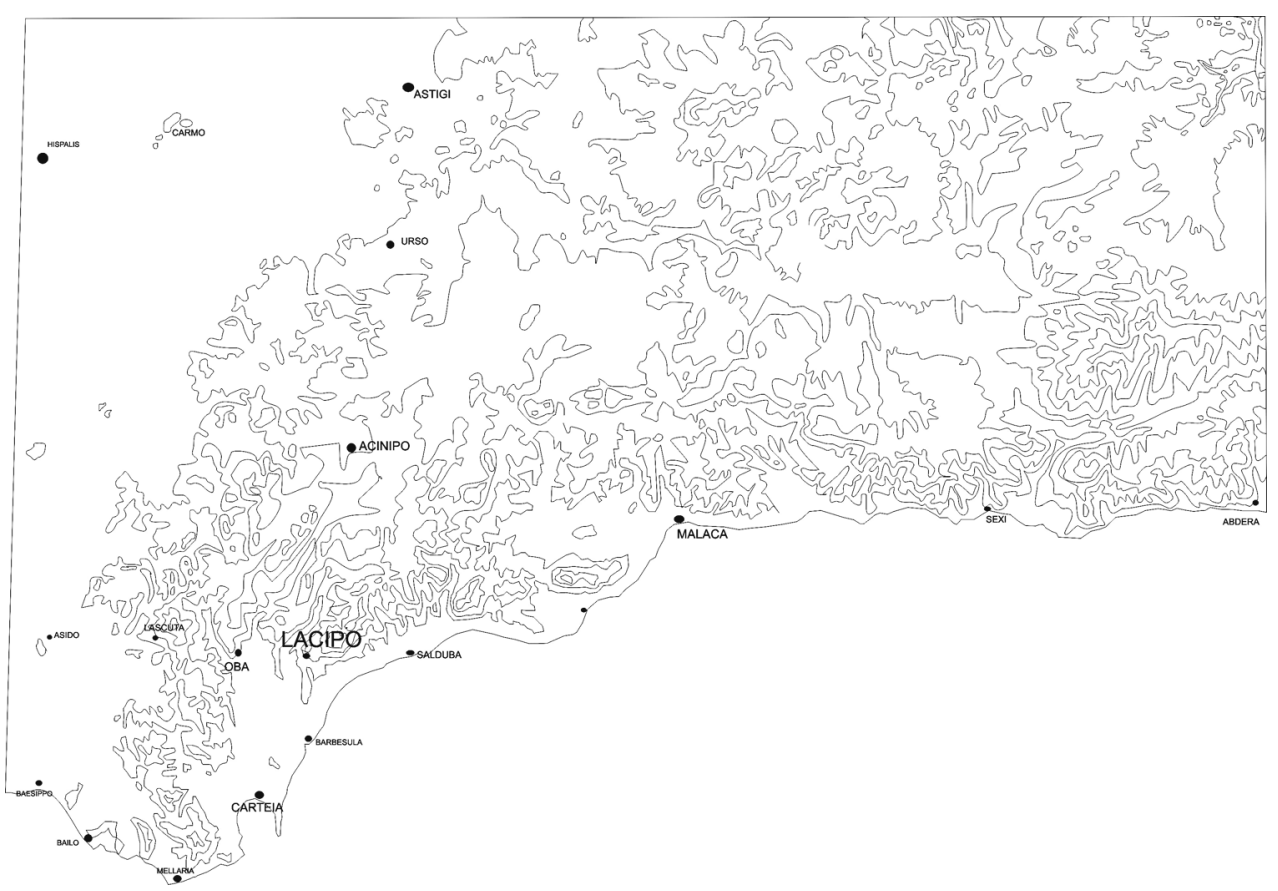

Fig. 12. El estrecho de Gibraltar entre los siglos IV a I a.n.e.

autores grecorromanos posteriores a la conquista) por Bástulos y Bastetanos. Siguiendo al Prof. García Moreno, los Mastienos serían los habitantes de la región adyacente al estrecho de Gibraltar y que luego serán conocidos como Bastetanos o Bástulos Penos (García, L. A., 2000: 104) mediante la ecuación Mastienos/Mastetanos/Bastetanos/Bástulos.

Lo cierto es que la zona donde se ubica nuestro asentamiento aparece en las fuentes literarias como susceptible de soportar estructuras de poder a nivel regional. Esto es lo que puede desprenderse de la noticia referida por Polibio ${ }^{11}$ y Livio ${ }^{12}$ referente a la rebelión del 197 a.n.e. cuyo protagonista, Culchas, dominaba entre otras las ciudades mastienas de Sexi y Malaca.

Con estos datos creemos suficientemente justificado la nomenclatura que hemos utilizado para nuestro primer periodo poblacional documentado durante esta segunda Fase de excavaciones en Cerro Colorado. Tras la misma, estamos en grado de sostener que nuestro asentamiento surge a mediados del siglo iv a.n.e. (merced a la aparición de barnices negros áticos) enmarcado en un proceso que se nos antoja mucho más amplio de reestructuración de la región mastiena provoca-

\footnotetext{
11 Historias, III, 11, 20 y III, 21, 11.

12 Ab urbe condita, XXVIII, 13, 3.
} 


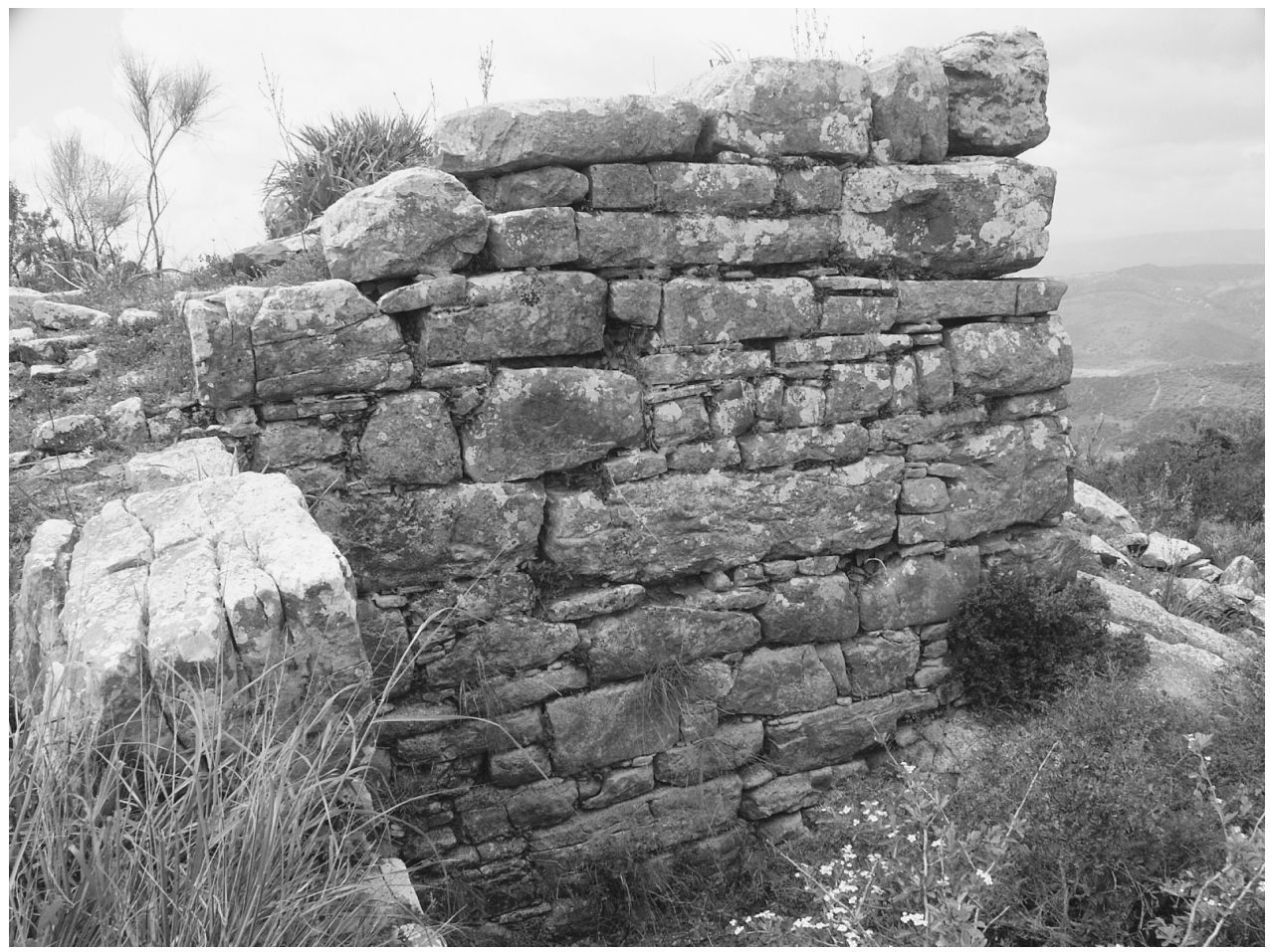

Fig. 13. Bastión Oeste de Lacipo (Casares, Málaga).

do por la firma del Tratado Romano cartaginés del año 348 a.n.e. Probablemente debamos su fundación al propio tratado al igual que otros centros del entorno como Lacipo o la refundación de la propia Carteia en la bahía de Algeciras.

La zona conoce un poblamiento bastante extenso desde finales del siglo VII a.n.e. (Recio, A., 2002: 46) con asentamientos como La Era en Benalmádena, Cerro del Castillo en Fuengirola, Roza de Aguado en Mijas, Arroyo Casablanca en Benalmádena, el cercano de Cerro Torrón en Marbella, Cerro Capellanía en Benalmádena, y el Torreón en Estepona (Suárez, J. 2001: 110 y ss) y que abarca hasta el siglo $v$ a.n.e. Será no obstante a partir de mediados del siglo IV a.n.e. cuando se produzca una reestructuración de estos poblados, desapareciendo algunos y surgiendo otros nuevos con claras características tipo Oppidum como sucede en Cerro del Águila (Estepona), Cerro Carretero (Gaucín) o Lacipo (Casares) (Bravo, S., 2000: 29). Dicha reestructuración debemos enmarcarla en la nueva situación y en las nuevas necesidades surgidas tras el tratado del 348 a.n.e. ${ }^{13}$. El tra-

${ }^{13}$ La bibliografía existente sobre el segundo tratado romano cartaginés es extensa y se tiene por probada la ubicación de Mastia de Tarsis en la Península Ibérica. Contra esta opinión Moret, P. (2002): «Mastia Tarseion y el problema geográfico del segundo tratado entre Cartago y Roma». Mainake, XXIV. Málaga. pp. 257 - 276. 
tado comportará la creación/refundación de una base militar púnico/cartaginesa en el estrecho que se localizará en Carteia ${ }^{14}$ llamada antiguamente Herakleia por Timóstenes ${ }^{15}$. Este último alaba su grandeza y su arsenal. Quizás el texto de Timóstenes contenido en Estrabón ha pasado desapercibido pero para nosotros adquiere especial importancia ya que muestra el carácter de la nueva ciudad: por un lado, su grandiosidad y suntuosidad se ve reflejada en las construcciones de tipo púnico llevadas a cabo en la ciudad empleando una trama urbanística de corte helenístico con puertas monumentales construidas con sillares almohadillados y lugares de culto (ROLDÁN, et alii, 2005:); por otro, la mención a su arsenal naval justifica su nacimiento. Carteia muy bien pudo nacer como base naval cartaginesa en territorio mastieno tras la firma del tratado del 348 a.n.e. Una base militar cartaginesa daría cohesión territorial y se enmarcaría en la red de compromisos y alianzas comerciales y políticas que se producen entre Cartago y el Sur de la Península Ibérica desde mediados del siglo IV a.n.e. como bien prueba el Pseudo Aristóteles ${ }^{16}$. Dicha fundación conllevaría el establecimiento de centros menores estrechamente dependientes de Carteia como Cerro del Aguila, Lacipo, Barbésula o nuestro Cerro Colorado, conformando una zona de influencia de los nuevos pobladores.

Las estructuras mastienas exhumadas durante la actividad del 2005 no permiten conjeturar nada sobre el carácter de las mismas o su funcionalidad. Lo único cierto es que parece que el asentamiento del siglo iv a.n.e. es de mayores proporciones que el del siglo III a.n.e. Esto lo observamos porque la muralla del siglo III a.n.e. corta las estructuras mastienas que continúan hacia el Sur, lo cual indicaría que, al menos en este sector, el poblado mastieno discurría más hacia el Sur que el posterior cartaginés. Por paralelos con asentamientos similares como La Era en Benalmádena o la Roza de Aguado en Mijas (Suárez, J. 2001: 123) pequeños asentamientos de este tipo surgen con una clara finalidad productiva: la minería en el caso de La Era y la agricultura en la Roza. No podemos aproximarnos siquiera a la funcionalidad de las estructuras excavadas por nosotros aunque por el material asociado a las mismas quizás nos encontráramos en un asentamiento dedicado a la elaboración de productos vinculados con el mar, en especial a las salazones. La gran cantidad de envases anfóricos (T-12.1.1.1 en su mayoría) y la aparición de barnices negros de importación hace pensar en la presencia de actividades comerciales llevadas a cabo en el asentamiento del siglo iv a.n.e., aunque la naturaleza de los muros excavados parece que debamos entenderlos como ambientes domésticos.

En la segunda mitad del siglo III a.n.e., tiene lugar una reestructuración total del poblado mediante un elemento arquitectónico que va a condicionar la fisonomía urbanística del poblado. Documentada en los Sondeos L, N y en la Zanja A/2, se ha conseguido exhumar los cimientos y parte del alzado (tres hiladas) de una muralla

${ }_{14}$ Así al menos se deduce de su mención en el Bellum Hispaniense, XXXII como praesidium navale y de su utilización como base naval por Lellio durante las últimas campañas del 207 a.n.e. referidas en Livio, XXVIII, 30, 1, 12.

15 Apud Estrabón, Geografía, III, 1, 7.

16 De Mir. Aus., 136. 
que creemos pudo delimitar el poblado de época púnica. Presenta una anchura media de 1,60 metros y está construida con una técnica muy común en asentamientos afines culturalmente. En el Sondeo $L$ es donde mejor ha podido ser documentada esta estructura por lo que nos ceñiremos para su descripción a los datos atestiguados en este Sondeo. La construcción de la muralla comporta la adecuación de dos líneas de encofre que servirán de guía a la misma; líneas que se asemejan a un opus quasivittatum con mampuestos careados al exterior. Para el caso que nos ocupa, la línea interior de la muralla estaría formada por las UU.EE $12014 / 12010$. El exterior de la muralla sigue la misma técnica aunque los mampuestos utilizados presentan mayor tamaño que los del interior utilizándose comúnmente la piedra local. Viene formada por la UE-12018. El interior de ambas líneas es rellenado por mampuestos irregulares de pequeño a mediano tamaño, sin carear y sin ligante entre ellos (UE-12019). No hemos documentado estructuras que adosen directamente a la muralla a modo de casamatas, como es común en estas construcciones; no obstante, cabe la posibilidad de que las UU.EE. 19016 y 19017 pudiesen formar parte de casamatas adosadas a la muralla. Lo mismo puede intuirse de la UE-13009 aunque dada la naturaleza de esta última, pensamos que pueda tratarse de un pequeño torreón.

La muralla recorre el perímetro del poblado por sus lados Sur, Oeste, Norte y se ha perdido en el sector Este aunque hemos podido documentar su derrumbe en el ángulo Noreste del mismo. Desde el Sur parte a una cota cercana a los 135 m.s.n.m. para alcanzar subiendo por la ladera Sur los 143 donde hemos detectado el desmantelamiento acaecido en 1999 durante la excavación de la zanja B. Sgue subiendo hasta la cota de los 145 m.s.n.m. donde se mantiene en los sectores Norte y Noreste donde perdemos su rastro.

En la zona Norte de la muralla hemos excavado lo que parece un vano abierto en la muralla conformando un ingreso directo enmarcado por dos estructuras (UU.EE. 1204 y 12010) que formarían los laterales de dicho ingreso. Tiene una anchura de casi tres metros sirviendo de suelo de uso (UE-13008) el sustrato geológico rebajado. Al Oeste de dicho ingreso se encuentra un muro con similar orientación aunque con una anchura menor que parece que adosaría con la muralla lo cual interpretamos, siguiendo paralelos para estos casos, como un torreón o pequeña casamata aunque el estado tan fragmentario de las estructuras exhumadas impide una clara adscripción a su funcionalidad.

Desconocemos el trazado de la muralla en la parte Noreste del cerro pues se han realizado dos sondeos y estos han tenido resultado negativo. No obstante, la misma la volvemos a recuperar en el ángulo Noreste del cerro, en el Sondeo N donde hemos podido localizar su estructura (UE-15016) y su derrumbe. Nada sabemos de la muralla en su lado Este aunque todo parece apuntar que existiría más al Este de la meseta superior actual. Los trabajos de extracción de tierras llevados a cabo en el cerro en la zona Este han debido destruir dicha estructura.

La muralla encierra un asentamiento urbano del que hemos podido excavar un edificio de planta rectangular en el Sondeo O, con orientación Noroeste - Sureste 


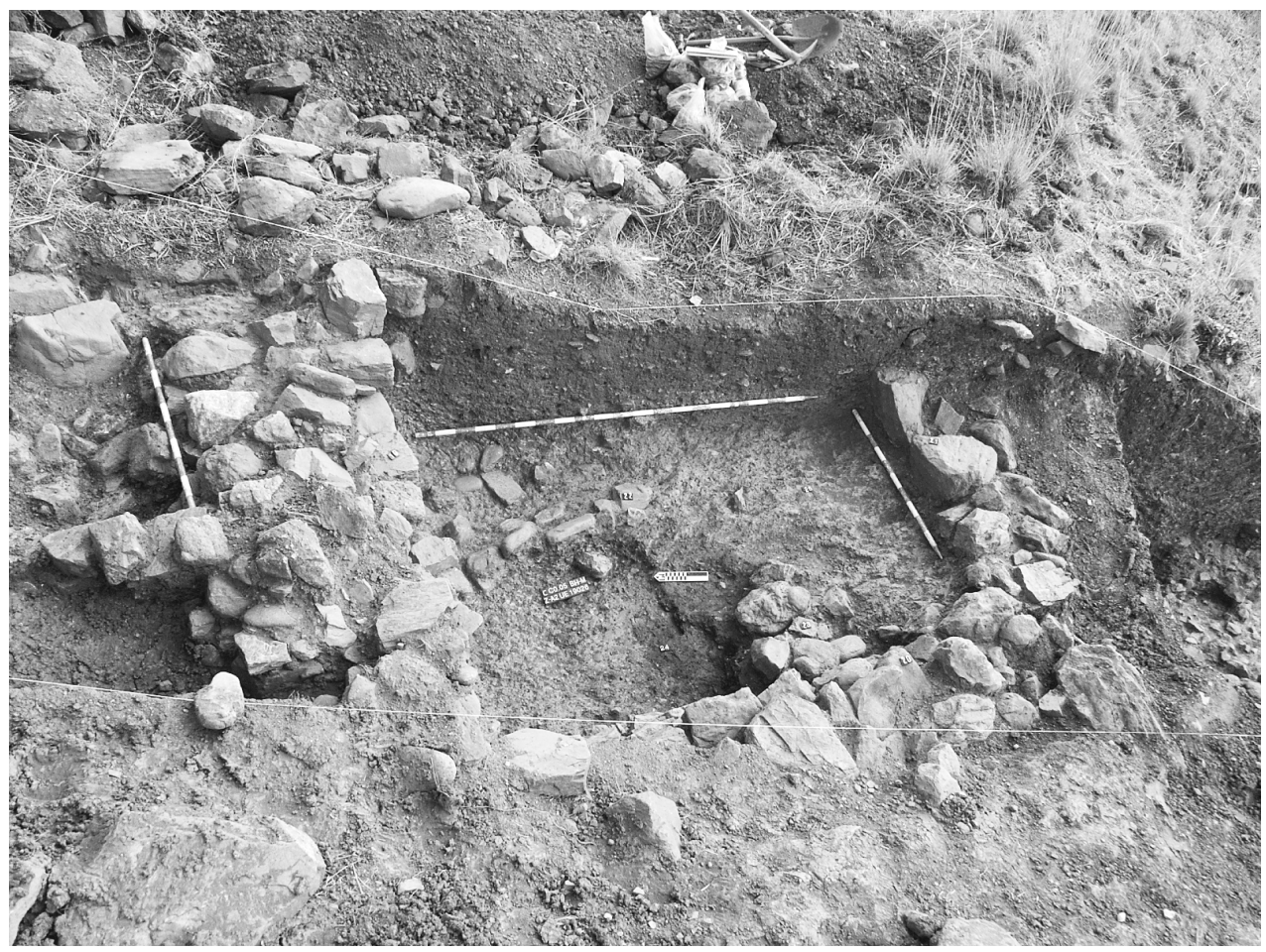

Fig. 14. Sondeo A/2. Habitación con hogar de época púnica.

formado por las UU.EE. 16019/16028/16026 y un suelo de lajas (UE-16022). Este edificio está en continua reparación pues sus suelos sufren hasta tres transformaciones durante el uso del edificio. Nada podemos decir sobre el carácter de dicha estructura. Los materiales vinculados a ella nada hacen dilucidar sobre su funcionalidad. Especial mención merece, no obstante, el hallazgo de un soliferrum en el nivel de amortización (UE-16016) de la estructura cuando ésta era ya en parte una ruina.

En la Zanja A/2 hemos podido delimitar igualmente dos estructuras urbanas. La primera es un muro que discurre en dirección Noreste - Suroeste (UE-19031) al cual se asocia un derrumbe de tapial (UE-19032). Debido a los condicionantes del Sondeo (2 metros de anchura) es imposible decir nada más sobre dicha estructura. Más al Sur, a unos 5 metros más abajo hemos delimitado una habitación cuadrangular formada por las UU.EE. 19019/19022/19026 a las que se asocia un suelo de tierra apisonada (UE-19026) y un hogar (UE-19024). Es el único ejemplo que tenemos de uso doméstico de una estructura durante este periodo.

A estas estructuras habría que sumar la exhumada en la esquina Sureste de la Zanja A/1 habitación cuadrangular formada por las UU.EE. 18008/18009 y que parecen estar en estrecha vinculación con el derrumbe de tapial UE-19031 por lo que 


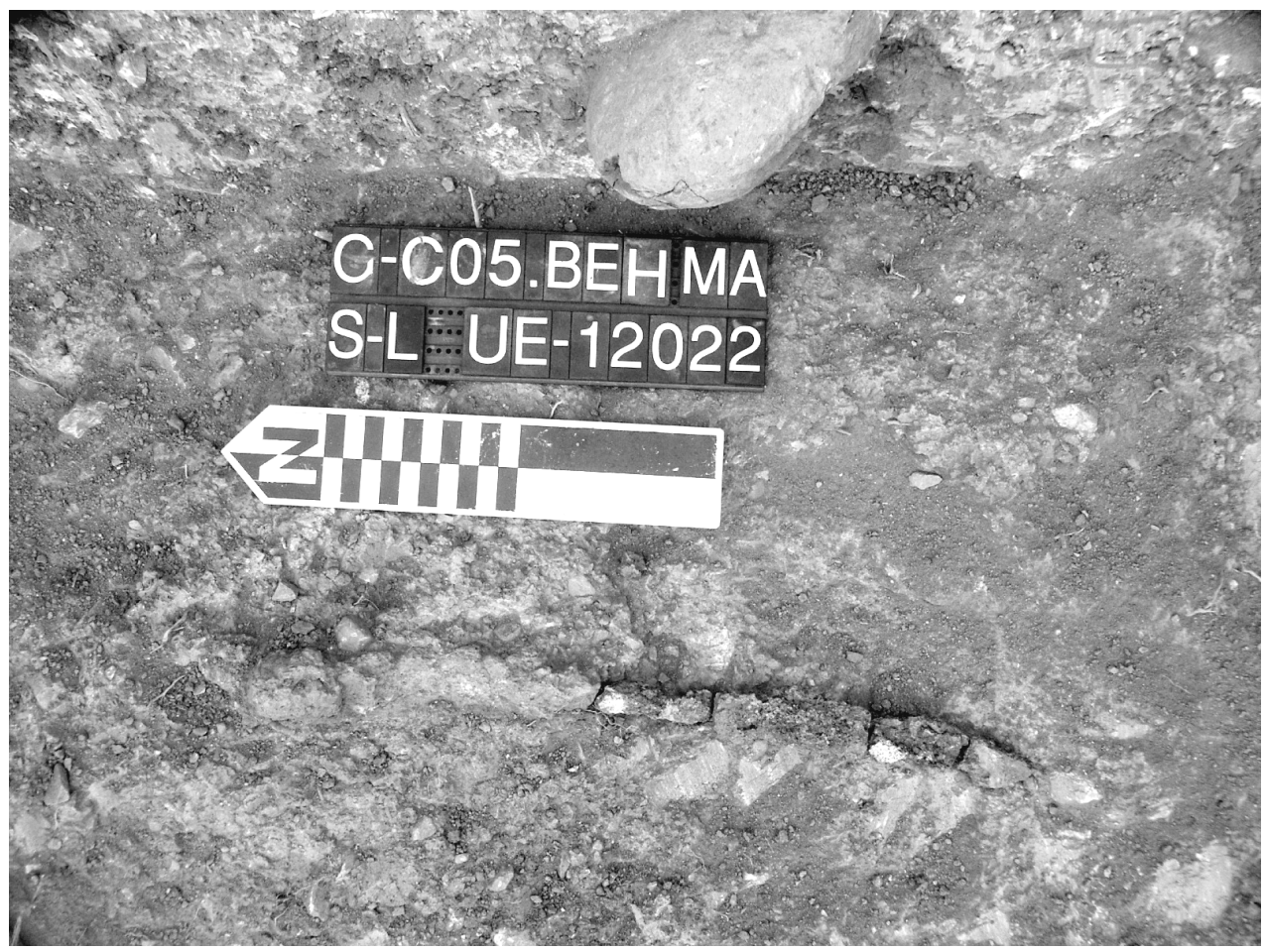

Fig. 15. Sondeo L. Daga de hierro en el momento de su hallazgo.

cabría la posibilidad de que dicho derrumbe fuese la pared de la estructura UU.EE. $18008 / 18009$.

A pesar del fragmentario estado de las estructuras, estamos en grado de asegurar que el poblamiento en época púnica se llevó a cabo disponiendo de, al menos la ladera Sur de forma aterrazada para lo cual se utilizarían muros de contención o bancales que servirían de contrafuertes a las estructuras domésticas excavadas en la Zanja A/2. Si nos fijamos en la planimetría de la Zanja A, podremos comprobar como existe un elemento separador que es la muralla UE-19015, verdadero elemento articulador del espacio, delimitando el interior urbano. Hacia el Sur encontramos el derrumbe de la muralla y un espacio que en época púnica aparece vacío y sujeto a la erosión constante de la pendiente. Al Norte de la muralla encontramos un espacio pleno de estructuras habitacionales dispuestas de manera aterrazada lo cual hace suponer que existirían deambulatorios o espacios circundantes a modo de calles con fuerte pendiente, probablemente zigzageantes para el uso de carruajes.

En la ampliación hacia el Este llevada a cabo en el Sondeo L, pudimos constatar la aparición de un nuevo muro de menores proporciones pero de similar factura que discurre en paralelo a la muralla y que está parcialmente destruido por 
construcciones republicanas y acciones contemporáneas. Dicha estructura (UE12052) a la cual viene asociado un suelo de cal (UE-12054) conforma un pasillo entre la muralla y esta estructura a modo de deambulatorio por el interior de la muralla del asentamiento. Esto tampoco es novedoso y en ciudades de su cultura como Kerkouane (Túnez), vemos similar solución urbanística. La anchura de este pasillo es de unos dos metros y medio, suficiente para el tránsito normal en una ciudad de sus características.

Vistos lo elementos exhumados durante esta fase de excavaciones, hemos propuesto dos momentos claramente identificables cronológicamente para este periodo. La llamada Fase I del Periodo Púnico la hemos fechado para sus inicios en el año 237 a.n.e. o un poco antes, en torno a mediados del siglo III a.n.e. en contextos de la Primera Guerra Púnica o, todo lo más, con el desembarco de Amilcar Barca en 237 a.n.e.

La gran remodelación que sufre la ciudad con la construcción de una muralla que rompe estructuras habitacionales mastienas hace pensar o bien en un cambio de población o bien en un cambio de estrategia poblacional. Quizás la llegada de nuevos contingentes poblacionales unido a las necesidades impuestas por la presión romana tras la derrota sufrida en la Primera Guerra Púnica y los siguientes conflictos africano (Guerra de los Mercenarios) y Sardo (Pérdida de la isla) harán que nuestro asentamiento se fortifique adquiriendo un carácter fuertemente africano por el modo de sus estructuras defensivas. Es cierto que los Barca darán cohesión a la zona y llevarán a cabo una política conciliadora con las poblaciones indígenas pues serán verdaderas fuentes de mercenarios para sus ejércitos. De todos es sabido que una de las principales preocupaciones de los Barca tanto en Iberia como luego en Italia, será la de proteger a sus aliados (Goldsworthy, A., 2002:273), aliados que para los mastienos, las mismas fuentes nos lo corroboran ${ }^{17}$. El pasaje no puede ser más importante por tratarse de una fuente de primera mano. Sabemos por Polibio y por Livio, que Aníbal en el año 205 a.n.e. hizo grabar en una estela de bronce en lengua púnica y griega durante su campaña italiana una especie de Res Gestae donde hablaba de sus aliados iberos entre los cuales menciona a los Mastienos. Dichos aliados muy probablemente combatirán con Aníbal en su periplo italiano y muchos serán licenciados y vueltos a sus lugares de origen.

La fecha de construcción de la muralla debe, por tanto, enmarcarse en estos momentos tan convulsos que van del año 240 al 237 a.n.e. El material recuperado y asociado a niveles de ocupación se basa principalmente en ánforas T-12.1.1.1 lo cual no afina mucho cronológicamente aunque la estrechez de sus cuellos puede llevarnos a los últimos decenios del siglo III a.n.e.

La Fase I de este periodo abarcaría por tanto desde os años 241/237 a.n.e. hasta el año 216 a.n.e. Efectivamente, el año 216 a.n.e. marca el inicio de una nueva Fase para nuestro yacimiento caracterizada por la destrucción gradual de las es-

\footnotetext{
17 Polibio, Historia, III, 33, 9.
} 


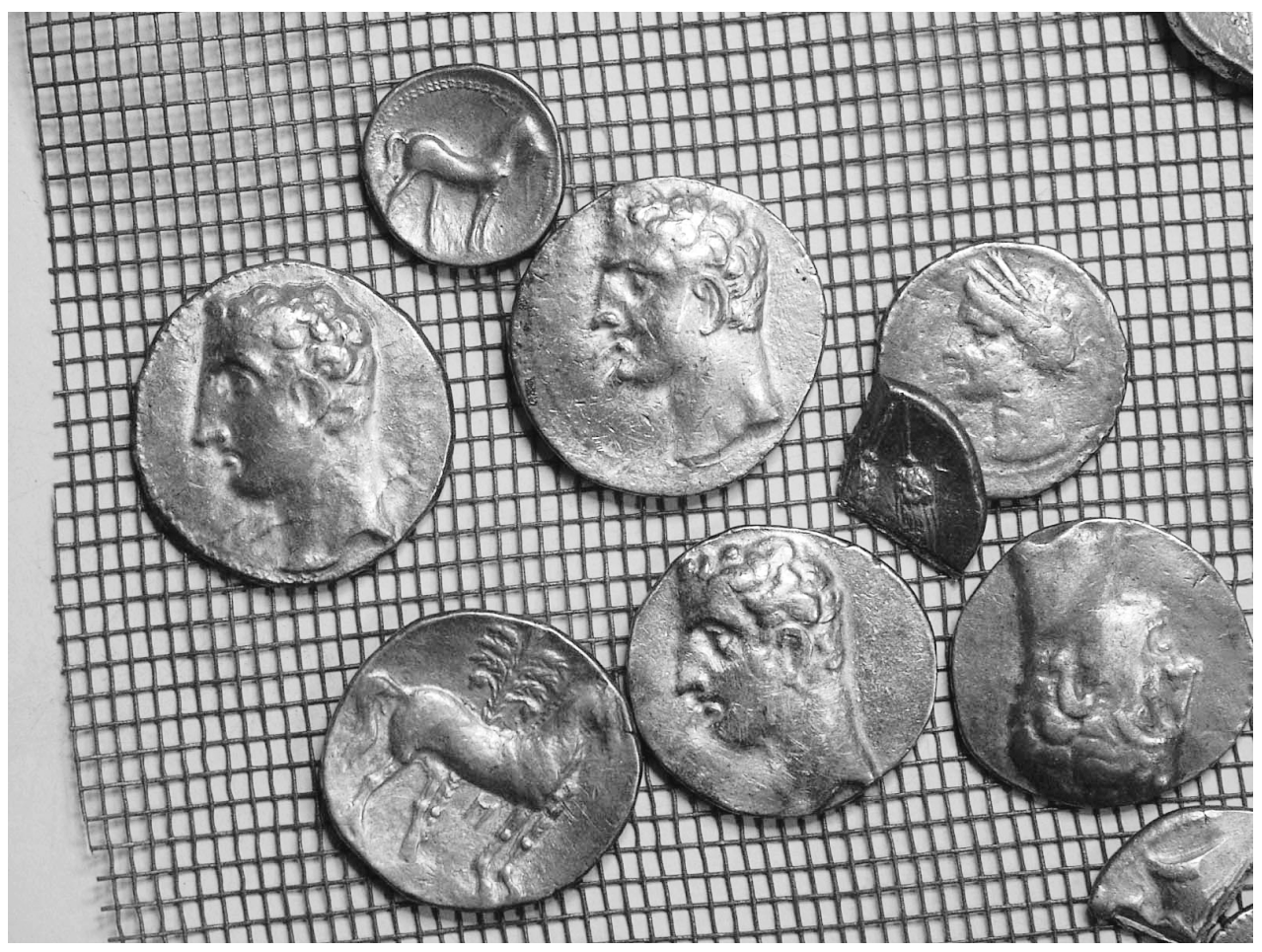

Fig. 16. Shekells hispano cartagineses aparecidos en el tesorillo tras su limpieza.

tructuras construidas apenas 30 años antes. Dicha ruina se ve en todos los sondeos donde se han localizado estructuras de la Fase I del Periodo Púnico a lo que hay que sumar el hallazgo de ánforas caídas en el suelo o en espacios abiertos (¿calle?) (caso del Sondeo O), objetos de metal tales como un soliferrum del Sondeo O y una daga del Sondeo $L$ y ausencia de niveles de incendio o destrucción. Por último, el hallazgo de un ocultamiento compuesto por tres orzas de cerámica común cargadas de plata incide en un desalojo traumático del asentamiento.

El año 216 a.n.e. es bastante problemático para la zona toda vez que el control bárquida se va haciendo cada vez más difícil por la presencia cada vez más cercana de las tropa romanas Así, según comenta Livio $^{18}$, los jefes navales cartagineses se sublevan contra Asdrúbal promoviendo una rebelión generalizada de todo el territorio Sur (in tartesiorum gente dice). Los sublevados, indígenas la mayoría, atacaron la ciudad de Asqua la cual liberó Asdrúbal poco después normalizando la situación. Para Ramón Corzo, esta Asqua debe corresponder con la Osqua romana, situada en el Cerro del León en la zona al Sur de Antequera por o que la rebelión tuvo que tener su origen en la región malagueña (Corzo, R. 1975:218). Puede que nuestro asentamiento sufriera los avatares de dicha sublevación pues no es

${ }_{18}$ Ab urbe condita, XXIII, 26, 5; $26-27$. 


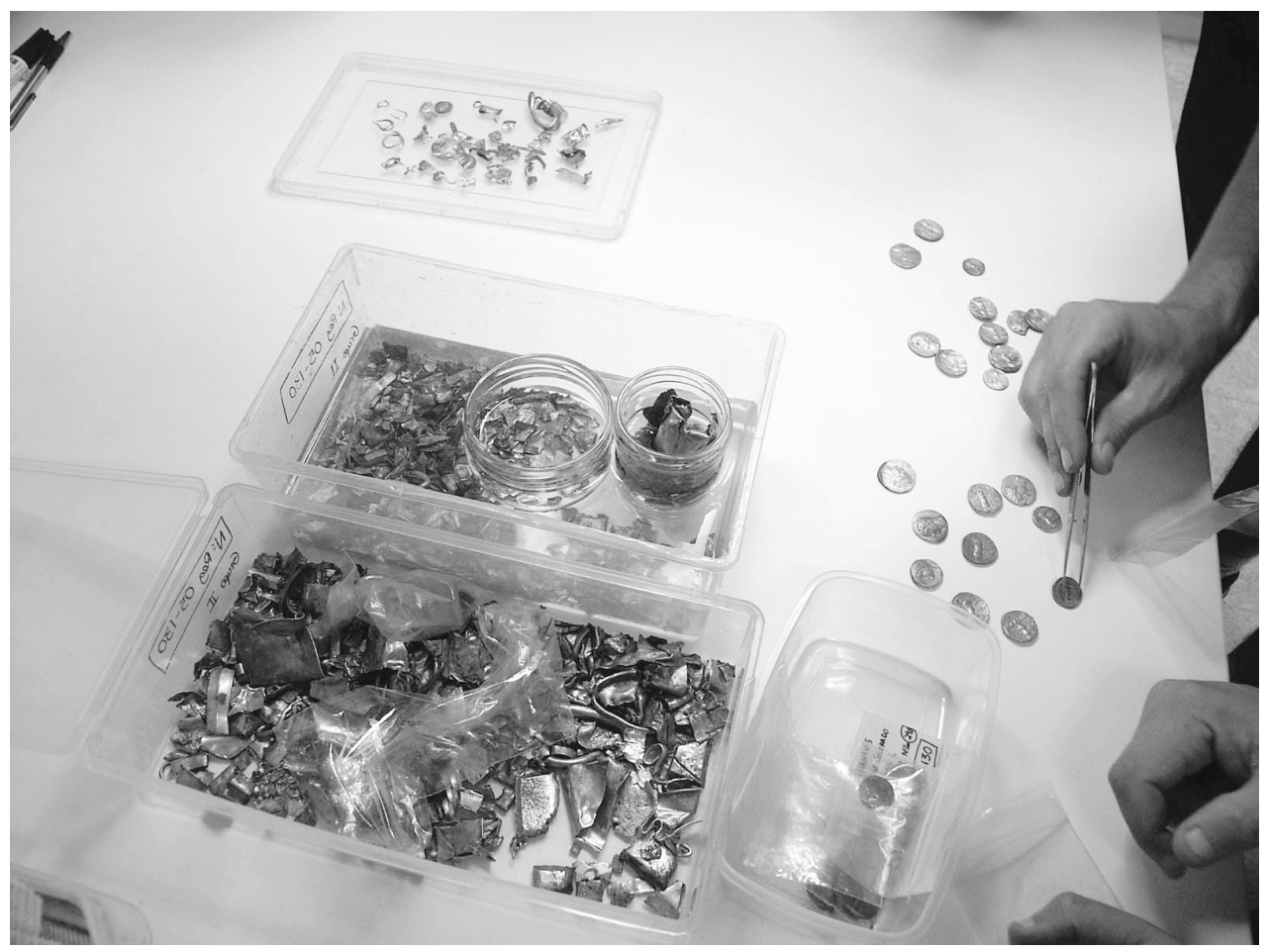

Fig. 17. Tesorillo cartaginés. Contenido de una de las orzas.

de extrañar que actuara como puerto de apoyo a las tropas cartaginesas asentadas en la Península.

Lo cierto es que el registro arqueológico presenta la ruina de la ciudad púnica construida 25 años antes, estado en el que va a seguir cuando los romanos lleguen a la zona el año 207 a.n.e.

No parece que se lleve a cabo una reconstrucción de ningún edificio; todo lo más se llevan a cabo pequeñas remodelaciones de suelos en el edificio excavado en el Sondeo O pero serán actuaciones sin importancia. El hallazgo de materiales en buen estado de conservación y que parece caído nos lleva a pensar en un abandono traumático de la ciudad por parte de sus pobladores.

Por Livio (XXVIII, 30, 3 - 12) sabemos que en la primavera del año 206 a.n.e., una escuadra romana al mando de Lelio, lugarteniente de Escipión se enfrentó a una cartaginesa al mando de Aderbal siendo derrotado éste último y huyendo a las costas africanas ${ }^{19}$. Este encuentro debió llevarse a cabo en la costa malagueña a

19 Lelio tenía su base en Carteia y sale al encuentro de una flota al mando de Aderbal que partiendo de Cádiz tenía como meta Cartagena. Ver Martínez Gázquez, J. (1988): «Encuentro romano-cartaginés en el estrecho: Livio XXVIII 30 3-12». Ier Congreso Internacional el Estrecho de Gibraltar. Ceuta, Noviembre de 1987. Tomo I. UNED. Madrid. pp. 725 - 729. 
muy poca distancia de Cerro Colorado toda vez que la escuadra romana salió desde Carteia. Este hecho ocurrido en la primavera del año 206 a.n.e. probablemente fuese el que propició el ocultamiento de un tesorillo compuesto por tres orzas de cerámica de cocina con sus respectivas tapaderas en cuyo interior se encontraron anillos, brazaletes, colgantes, pendientes, cadenas, vasos y recortes de plata, además de monedas hispano - cartaginesas y romano - campanas. Dicha ocultación se produce en la UE-12008, nivel parcialmente cortado a techo por acciones de nivelación romanas pero que está sellando en parte el derrumbe de la muralla púnica. No hay duda sobre la fecha del ocultamiento toda vez que encontramos monedas acuñadas en 209 a.n.e. por lo que la ocultación debe corresponder a la presencia de Lelio en estas $\operatorname{costas}^{20}$.

Por tanto, durante el Periodo Púnico hemos distinguido dos Fases claramente diferenciadas por las acciones que se llevan a cabo en el yacimiento. En la Fase I que podemos encuadrar cronológicamente entre los años 40 del siglo III a.n.e. y el 216 a.n.e. tiene lugar una fuerte remodelación del poblado con la construcción de una muralla que circunda el asentamiento y que hemos podido detectar en sus lados Sur, Oeste y Noreste: Enmarcada en esta cerca se encuentra una ciudad con un urbanismo desarrollado en torno a construcciones aterrazadas donde se colocarán las estructuras arquitectónicas, en especial las de ambiente doméstico. También se lleva a cabo la construcción y remodelación de un gran edificio de planta cuadrangular en la parte superior de la meseta.

Quizás motivado por la rebelión tenida lugar en 216 a.n.e. contra el poder barca establecido en la zona malagueña, la ciudad comienza un proceso de abandono y derrumbe de sus estructuras que llegará a su cenit con la aparición de las primeras tropas romanas en 206 a.n.e. Coincidiría con nuestra propuesta de Fase II de éste Periodo. Lo entendemos así toda vez que no hemos apreciado en ninguno de los sondeos excavados, signos de violencia como incendios, derrumbes intencionados, etc. Sí hemos comprobado un paulatino y lento proceso de ruina de las estructuras defensivas así como remodelaciones de suelos hasta el abandono apresurado del asentamiento merced al hallazgo de ánforas T-12.1.1.1 caídas en los suelos y espacios abiertos, armas tales como un soliferrum y un cuchillo de pomo redondo y un tesorillo conteniendo innumerables objetos de plata cuya datación por las monedas más modernas no iría más allá del año 209 a.n.e.

Inmediatamente tras la conquista romana del asentamiento el año 206 a.n.e., nuestro poblado sufre una nueva remodelación urbanística. Los nuevos pobladores parece que no tienen en cuenta las precedentes estructuras urbanas y llevan a cabo un importante proceso de renovación urbanística, cambiando los ejes de la ciudad $^{21}$ precedente y modificando sustancialmente la planimetría urbana del asentamiento.

20 Debido a las especiales características del hallazgo y a la naturaleza de este trabajo, el estudio de los materiales se está llevando a cabo en estos momentos.

21 Estructuras romano republicanas fechadas a inicios el siglo II a.n.e. rompen perpendicularmente la muralla púnica en sus lados Oeste y Noreste. 
No obstante, poco podemos decir de este periodo a nivel constructivo ya que el rebaje ocasionado antrópicamente en 1999 ha destruido casi totalmente los niveles romanos. Sabemos por planimetría antigua que la cima del cerro se encontraba a una cota de 150 m.s.n.m. Sin embargo, hoy día nos encontramos un cerro amesetado artificialmente cuya cota superior está a 146 m.s.n.m. Estos cuatro metros de potencia arqueológica que fueron sesgados en 1999 han supuesto una pérdida irreparable para el patrimonio arqueológico andaluz que intentaremos, no obstante, reconstruir por los pocos restos conservados del $\mathrm{Pe}$ riodo Romano.

En el ámbito estructural, los Sondeos L, Ñ y A/1 son los únicos que han deparado algún resto constructivo. Se trata de muros de mampostería, cimentaciones en el caso de los Sondeos $L$ y $\tilde{N}$ que rompen a la muralla púnica por lo que entendemos que este elemento dejó de estar en uso cuando se acomete esta nueva reestructuración urbanística en el asentamiento. En la Zanja A/1, hemos detectado una estructura cuadrangular realizada en opus vittatum aunque en muy mal estado de conservación. El material adscrito, campanienses $\mathrm{A}$ antiguas y medias, cubiletes de paredes finas y ánforas T-7.4.2.1 y T-8.1.1.1. obliga a llevarnos dicho horizonte a inicios del siglo II a.n.e. Es de destacar la acción que se lleva a cabo en el Sondeo $L$ donde la UE-12003 ha sido interpretada como un vertido de nivelación para la colocación de un suelo asociado a la cimentación UE-12004. Sin embargo, la demolición efectuada en 1999 ha destruido el techo de esta UE-12003 por lo que no conocemos su potencia ni, por supuesto, el suelo de uso. Es de reseñar la gran cantidad de material adscribible cronológicamente al siglo II a.n.e. entre las que destacan las ánforas grecoitálicas y las T-7.4.2.1., así como tipos iberopúnicos e imitaciones de formas de barnices negros como platos de pescado Lamb. 23 o vasos de paredes finas. El hallazgo de ánforas grecoitálicas prueba la presencia de gentes que demandan vino itálico lo cual hace pensar en la presencia de itálicos en nuestro yacimiento.

Por lo que respecta al devenir histórico de nuestro asentamiento, aunque con una parquedad casi desesperante por parte de las fuentes, no obstante estamos en grado de avanzar sobre el desarrollo histórico de la zona en los momentos inmediatos a la conquista romana y su posterior desarrollo poblacional. Llamativo es, sin embargo, el hecho de que las fuentes silencien acontecimientos que tendrían cierta relevancia en la integración y asimilación de comunidades urbanas perfectamente formadas en el organigrama administrativo romano. Este dato, aunque negativo en principio a los ojos del investigador, resulta precioso por lo que encierra en sí mismo. Los autores romanos cuentan los hechos anormales y dignos de mención en cuanto a un sutil juego narrador - espectador. Lo cotidiano, la normalidad no interesa. Esta característica de normalidad absoluta de la zona (reflejada en la carencia de fuentes al respecto) debemos entenderla como un continuismo poblacional en las estructuras económicas, políticas y sociales en el territorio objeto de estudio.

A partir de este momento, las poblaciones hispanas habitantes del litoral malagueño occidental serán tratadas como ciudades dediticias y sujetas al pago de un 


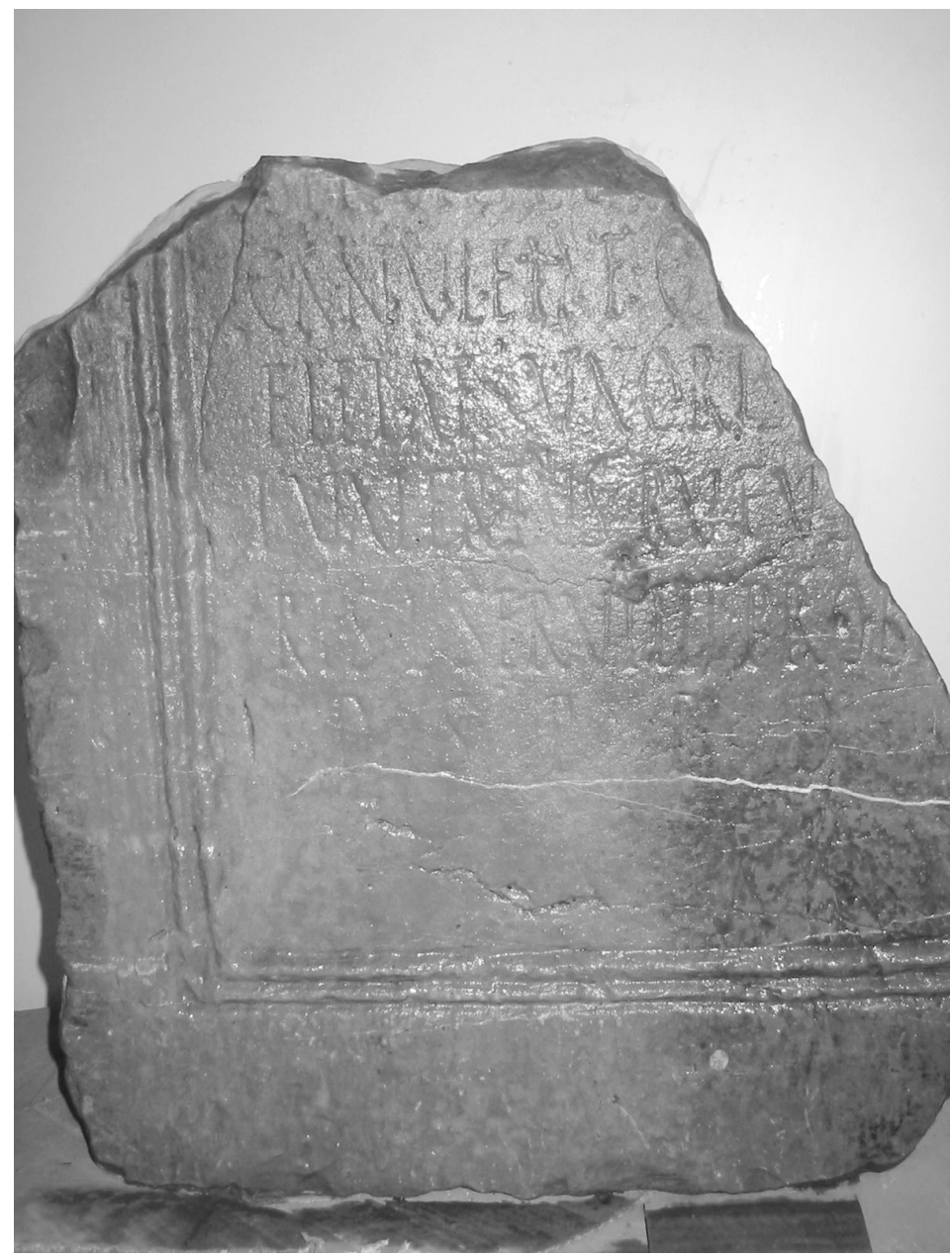

Fig. 18. Epígrafe relativo a la Gens Canuleia. (Carteia, San Roque, Cádiz).

stipendium. La situación cambiará tras la gran sublevación ${ }^{22}$ del año 197 a.n.e. cuando las ciudades sometidas a Roma entablarán relaciones basadas más en la amicitia que en el enfrentamiento toda vez que algunas (caso de Suel o Salduba), aparecerían a los ojos de Roma como unidades administrativas urbanas, esto es, verdaderas ciudades y, por tanto, distintas de las comunidades del interior mas extrañas al concepto de urbanismo antiguo. Nuestro asentamiento se encontraría a medio camino entre las grandes unidades urbanas tipo Suel, Malaka o Salduba y los pequeños asentamientos dependientes de estos centros redistribuidores. Situación que queda reflejada en la petición que una delegación de hispanos pone en conocimiento del Senado en 171 a.n.e. referida por Livio (XLIII, 2, 12).

22 Livio, XXXIII, 21, 6; Apiano, Iber., 39. 
Hasta mediados del siglo II a.n.e., la zona está sujeta a la amenaza del clima bélico que se vive en la Península. Prueba de ello es la cita de Apiano el cual refiere cómo el caudillo lusitano Púnico ataca a los Blastofenices, habitantes de la zona ${ }^{23}$.

En este estado de cosas y con el clima bélico ininterrumpido que se vive en la Península desde prácticamente la conquista romana, el asentamiento de Cerro Colorado se conformará como una zona en la periferia de la guerra donde las oligarquías ciudadanas llevarían a cabo un proceso de integración en la administración romana por medio de instituciones como la clientela o el hospitium.

La familia de los Cornelios y sus parientes los Fabios se constituirán en verdaderos patronos de las oligarquías de estos poblados lo que provocará una situación más favorable de las mismas con relación a Roma. Por tanto, aunque las fuentes silencian cualquier noticia al respecto, es lógico considerar que los mismos no fueran tratados como ciudades estipendiarias, articulándose de otra manera, caso al parecer de Malaka ${ }^{24}$. Lo cierto es que sabemos que Barbesula, Lacipo y Salduba eran tenidas todavía por ciudades estipendiarias a mediados del siglo । si hacemos caso a Plinio.

Las aspiraciones de estas ciudades a integrarse definitivamente en Roma no van a agotarse y será por medio del hospitium o la clientela como logren sus objetivos. Prueba de ello es la aparición de gentilicios vinculados con las grandes familias protagonistas de la conquista como los fabii en Lacipo (CIL II, 1938) y Barbesula (CIL II, 1941) y los Servilii en Lacipo (CIL II, 1937). También de Lacipo parece provenir un epígrafe que se encuentra en la actualidad en Carteia haciendo referencia a la gens canuleia ${ }^{25}$ lo cual probaría la fuerte vinculación/dependencia de Lacipo con la ciudad de Carteia y su promotor, el pretor del año 171 a.n.e. Lucio Canuleio, vinculación subrayada ya desde el Periodo Púnico de Cerro Colorado.

Las fuentes son parcas a la hora de acercarnos a lo sucedido en la costa occidental malagueña durante finales del siglo II e inicios del I a.n.e. hasta el episodio de Sertorio el cual se vio forzado a realizar un periplo de algunos años por la zona. Tras ser perseguido por C. Annio, Sertorio buscó refugio el año 81 a.n.e. en la posterior Mauritania Tingitana y expulsado, volvió a la Península muy probablemente a la costa malagueña, siendo de nuevo rechazado (Plutarco, Sert. 7, 6). El dato, aunque impreciso, es importante debido a que constata el dominio de la zona donde se ubica nuestro yacimiento por $C$. Annio, lugarteniente de Sila ${ }^{26}$. También re-

23 Iber., 56 - 58 .

24 El tan controvertido pasaje de Plinio III, 8 donde se cita a Malaka y a su río de los federados pudiera enmarcarse en este nuevo contexto de relaciones con Roma pues no nos parece lógico que tuviera el estatuto de federada desde la conquista toda vez que fue una de las ciudades participantes en la rebelión del año 197 a.n.e.

25 Noticia recogida de la ponencia que el Prof. Rodríguez Oliva pronunció en las las Jornadas de Arqueología del Campo de Gibraltar que tuvieron lugar en Tarifa en 2004.

26 Sobre la huída de Sertorio ver: García Mora, F. (1994): «El conflicto sertoriano y la provincia Hispania Ulterior» Actas del II. ${ }^{\circ}$ Congreso de Historia de Andalucía, Córdoba, 1991. Córdoba. pp. 271 - $286 . ;$ Idem: (1995): «El periplo sertoriano» II. ${ }^{\circ}$ Congreso Internacional El Estrecho de Gibraltar. Ceuta, Noviembre de 1990. UNED. Ceuta. pp. 197 - 209. 
fuerza este razonamiento el hecho de que en 76 a.n.e., Pompeyo se dirigiera contra las bases sertorianas de Cartagonova y Dianium que interrumpían las rutas comerciales con el sur peninsular.

En este estado de cosas, nuestro asentamiento parece sufrir los avatares del conflicto sertoriano toda vez que por los materiales recuperados durante esta segunda Fase, la ocupación del mismo parece terminar en los inicios del siglo I a.n.e.

El cerro no volverá a ser ocupado hasta prácticamente la actualidad. Es lo que hemos convenido en denominar Periodo IV. Durante el mismo, que se inicia en fecha indeterminada aunque todo parece apuntar a mediados del siglo XIX, se lleva a cabo en el cerro un abancalamiento para construir terrazas con mampuestos tomados de las estructuras antiguas. En algunos casos dichos bancales apoyan directamente sobre muros antiguos y en otros muchos se toman estructuras antiguas emergentes como bancales.

El cerro se estructura así en cuatro anillos que van formando plataformas más o menos planas donde cultivar olivares y caña de azúcar. En la cota de 120 m.s.n.m. tenemos el primero y más extenso, el cual recorre el perímetro de todo el cerro. UN segundo cinturón de bancales se aprecia en la cota de los 135 m.s.n.m. Otro en los 140 y el último en la cota de los 145 m.s.n.m. Hemos podido documentar varios de estos bancales y sus relaciones con las estructuras antiguas. En la Zanja A/1, la UE-18010 se configura como un bancal perteneciente

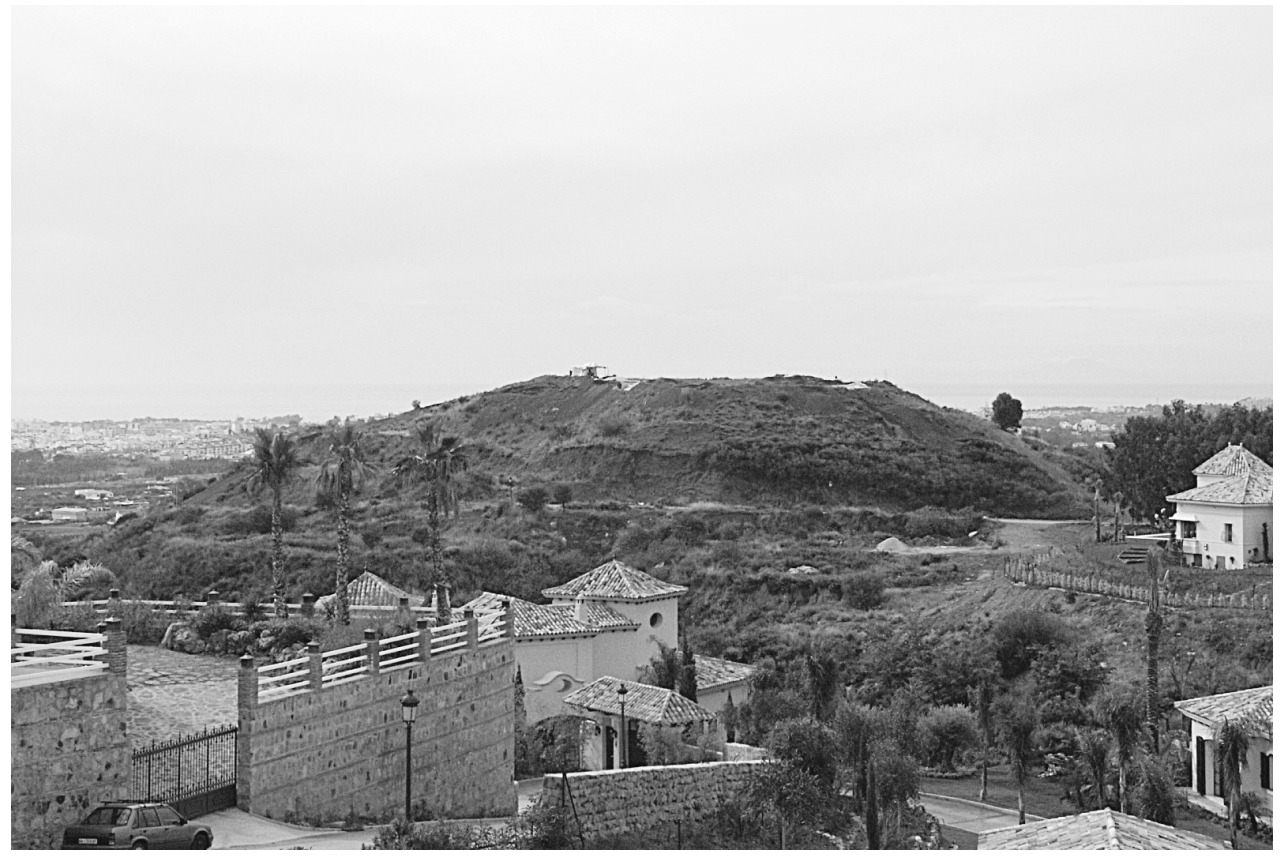

Fig. 19. Cerro Colorado en la actualidad. 
al Periodo IV, estructura que aparece justo encima del muro UE-18003. La diferencia constructiva es manifiesta ya que la UE-18010 se presenta como un alineamiento de piedras sin ligante y sin líneas de careo. La estructura UE-18003 es bastante más consistente con líneas de careo y mampuestos trabados con ligante a base de barro local.

Estas estructuras parecen confirmar el uso que tuvo el cerro, perteneciente al Cortijo Colorado desde finales del siglo xIx. Como apunta José Luís Casado (CASADO, J. L., 2003:20), ante la dejación de la administración en la época de la Restauración y el inmenso fraude fiscal que generaba el campo, se llevó a cabo un Catastro en las tierras pertenecientes a Marbella en 1897 aunque sin éxito por lo que se impuso desde 1906 el Parcelario cuya base era la parcela referida al tipo de cultivo y a su propietario. Para la redacción del Catastro de 1897 se formó una Comisión de Evaluación con la pretensión de obtener una visión general del campo marbellí. Los trabajos de esta Comisión se encuentran en el Archivo Municipal de Marbella y en el Archivo Histórico Provincial de Málaga. En ellos se lleva a cabo un amillaramiento de los terrenos y sus rendimientos y una valuación de las superficies, dividiendo el Término Municipal en seis secciones denominadas con las letras de la $\mathrm{A}$ a la F. Por la situación del Cerro Colorado, a nosotros nos interesa la sección B (ver planimetría antigua) ubicada entre los ríos Guadaiza y Verde con la mitad de sus tierras pertenecientes a la Colonia de El Ángel productora de caña de azúcar. Por dicho catastro sabemos que las parcelas situadas al Norte de la Ferrería de La Concepción estaban sembradas de remolacha azucarera.

\section{BIBLIOGRAFÍA}

AQUILUÉ ABADÍAS, X., GARCÍA ROSELLÓ, J., GUITART DURAN, J., (coord.) (2000): «La ceràmica de vernís negre dels segles II i I aC: Centres productors mediterranis i comercialització a la Península Ibèrica», en Actas de la Taula rodona, Empúries, 4 i 5 de juny de 1998. Museo de Mataró. Mataró.

BELTRÁN LLORIS, M. (1990): Guía de la cerámica romana. Zaragoza.

BLÁZQUEZ MARTÍNEZ, J. M. a y GARCÍA-GELABERT, M. ${ }^{a}$ P. (1998): «Los bárquidas en la Península Ibérica». Atti del II. ${ }^{\circ}$ Congresso Internazionale di Studi Fenici e Punici. Roma, 9-14 novembre 1987, Roma 1991, vol. 1. pp. 27-50.

BRAVO JIMÉNEZ, S. (2000): «Evolución Del poblamiento fenicio en la costa mediterránea andaluza». E.T.F. Serie II, 13. Historia Antigua. UNED. Madrid. pp. $13-44$.

BRAVO JIMÉNEZ, S. (2003): «Un pueblo prerromano en el estrecho de Gibraltar: Los Li-

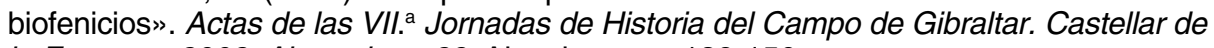
la Frontera, 2002. Almoraima, 29. Algeciras. pp. 139-150.

CASADO BELLAGARZA, J. L. (2003): «Ocultación de la riqueza agraria en el municipio de Marbella. El catastro de 1897. Cilniana, 16. Imágenes de Marbella, VIII. Marbella. pp. 839.

CORZO SÁNCHEZ, R. (1975):»La segunda guerra púnica en la Bética». Habis, 6. Sevilla. pp. 213-240.

DÍAZ TEJERA, A. (1997): «Polibio 3, 24, 1. El segundo tratado entre Roma y Cartago. Problemas de interpretación y textuales». Xaire. II. ${ }^{a}$ Reunión de historiadores del mundo griego antiguo (Sevilla, 18-21 de diciembre de 1995). Homenaje al Prof- F. Gascó. Sevilla. pp. 261-268. 
ENCICLOPEDIA DELL'ARTE ANTICA Classica e Orientale (1979): Atlante delle forme ceramiche. Roma.

GARCÍA MORENO, L. A. (2001): « «. De Gerión a César. Estudios históricos y filológicos de la España indígena y Romano-republicana. Alcalá de Henares. pp.

GARCÍA SÁNCHEZ, M. (1997): «Epigrafía anfórica de Mascastellar-Pontós: ánforas grecoitálicas y masaliotas». Pyrenae, 28. Barcelona. pp. 257-269.

GOLDSWORTHY, A. 2002): Las guerras púnicas. Barcelona.

HARRIS, E. C. (1991): Principios de estratigrafía arqueológica.

JIMÉNEZ ÁVILA, J. y ORTEGA BLANCO, J. (2004): La Cerámica griega en Extremadura. Cuadernos Emeritenses, 28. MNAR. Mérida.

$\mathrm{KOCH}$, M. (2003): Tarsis e Hispania. Estudios histórico-geográficos y etimológicos sobre la colonización fenicia de la Península Ibérica. CEFYP. Madrid.

LAMBOGLIA, N. (1952): «Per una classificazione preliminare della ceramica campana». Atti del $I^{\circ}$ Congresso Internazionale di Studi Liguri. Bordighera, 1952. pp. 139-206.

MANCILLA CABELLO, M. ${ }^{a}$ I. (2004): «La vajilla de barniz negro de Pollentia: la habitación $\mathrm{H}$ ». Arqueología y Territorio, 1. Granada. pp. 135-153.

MAYORGA, J. et alii. (2001): «Informe de la Prospección Arqueológica de Urgencia sobre el trazado de la autopista de la Costa del Sol. Tramos Fuengirola-Marbella y Marbella-Estepona». Anuario Arqueológico de Andalucía/1996. Sevilla. pp. 360-376.

MOREL, J. P. (1965): Céramique à vernis noir du Forum Romain et du Palatin. París.

RAMON TORRES, J. (1995): Las ánforas fenicio-púnicas del Mediterráneo central y occidental. Barcelona.

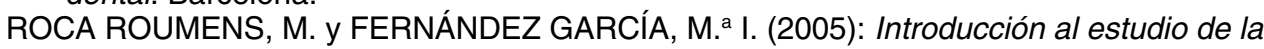
cerámica romana. Málaga.

RODERO, A. (1995): Las ánforas prerromanas en Andalucía. Bologna.

SANMARTÍ GREGO, J., PRINCIPAL PONCE, J. (1998): «Cronología y evolución tipológica de la Campaniense A del siglo II a.C.: las evidencias de los pecios y de algunos yacimientos historicamente fechados". Arqueomediterránea 4. Treballs de l'área d'arqueologia de la Universitat de Barcelona, Barcelona. pp. 193-215.

VV. AA (1989): Amphores romaines et histoire èconomique: dixs ans de recherches: Actes du colloque de Sienne (22-24 mai 1986). Colletions de l'Ėcole Française de Rome, 114. Paris y Roma.

(2002): « «. Mainake, XXIV. Colonizadores e indígenas en la Península Ibérica. Málaga. 


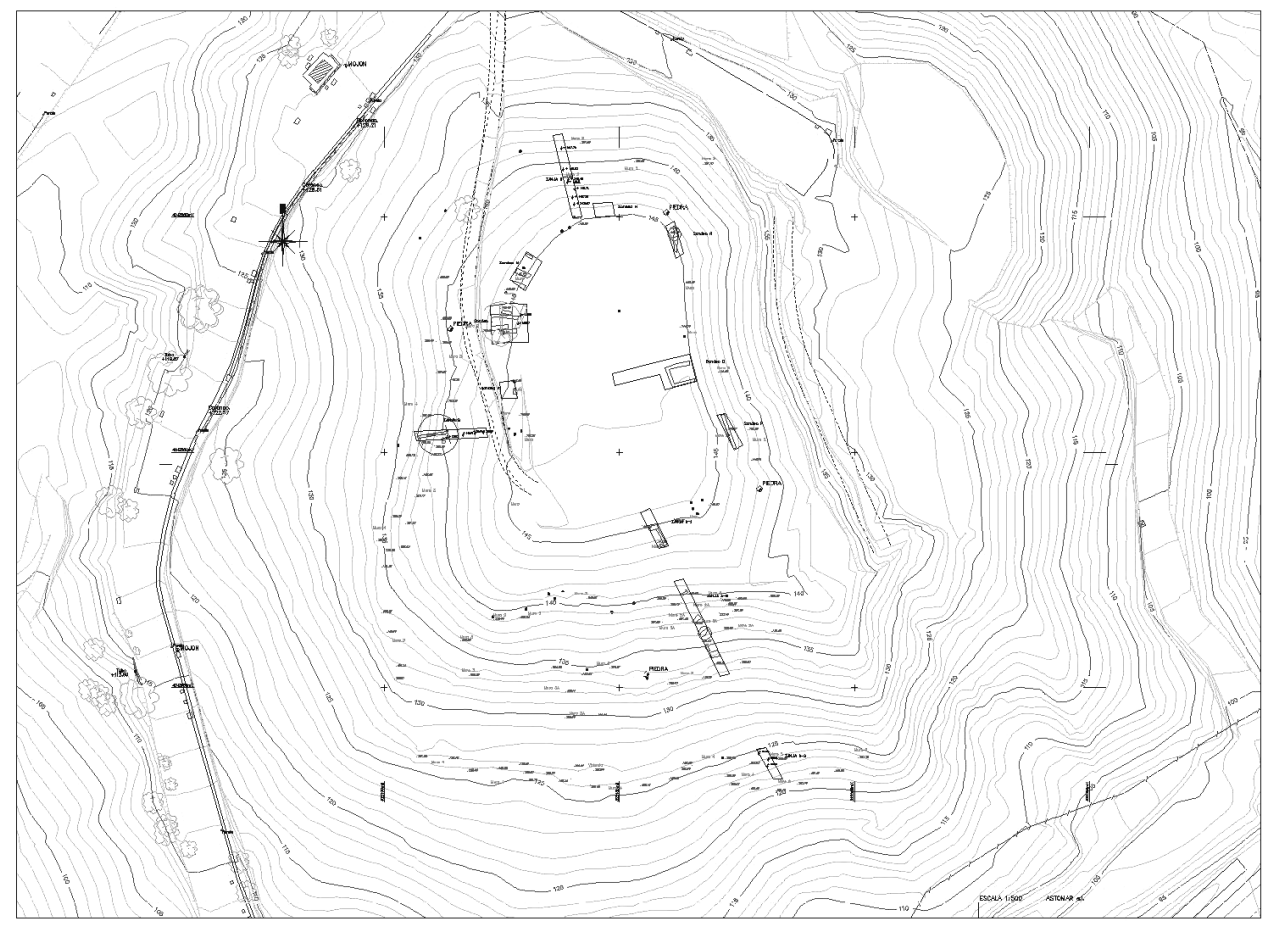

Lám. 1. Plano de situación del yacimiento con los sondeos arqueológicos efectuados. 